IZA DP No. 7026

Population Policies, Demographic Structural Changes, and the Chinese Household Saving Puzzle

Suqin $\mathrm{Ge}$

Dennis Tao Yang

Junsen Zhang

November 2012 


\title{
Population Policies, Demographic Structural Changes, and the Chinese Household Saving Puzzle
}

\author{
Suqin Ge \\ Virginia Tech \\ Dennis Tao Yang \\ University of Virginia \\ and IZA \\ Junsen Zhang \\ Chinese University of Hong Kong \\ and IZA
}

\section{Discussion Paper No. 7026 \\ November 2012}

\author{
IZA \\ P.O. Box 7240 \\ 53072 Bonn \\ Germany \\ Phone: +49-228-3894-0 \\ Fax: +49-228-3894-180 \\ E-mail: iza@iza.org
}

\begin{abstract}
Any opinions expressed here are those of the author(s) and not those of IZA. Research published in this series may include views on policy, but the institute itself takes no institutional policy positions. The IZA research network is committed to the IZA Guiding Principles of Research Integrity.

The Institute for the Study of Labor (IZA) in Bonn is a local and virtual international research center and a place of communication between science, politics and business. IZA is an independent nonprofit organization supported by Deutsche Post Foundation. The center is associated with the University of Bonn and offers a stimulating research environment through its international network, workshops and conferences, data service, project support, research visits and doctoral program. IZA engages in (i) original and internationally competitive research in all fields of labor economics, (ii) development of policy concepts, and (iii) dissemination of research results and concepts to the interested public.
\end{abstract}

IZA Discussion Papers often represent preliminary work and are circulated to encourage discussion. Citation of such a paper should account for its provisional character. A revised version may be available directly from the author. 
IZA Discussion Paper No. 7026

November 2012

\title{
ABSTRACT \\ Population Policies, Demographic Structural Changes, and the Chinese Household Saving Puzzle*
}

\begin{abstract}
Using combined data from population censuses and Urban Household Surveys, we study the effects of demographic structural changes on the rise in household saving in China. Variations in fines across provinces on unauthorized births under the one-child policy and in cohort-specific fertility influenced by the implementation of population control policies are exploited to facilitate identification. We find evidence that older households with a reduced number of adult children save more because of old-age security concerns, middle-aged households experience an increase in saving due to the lighter burden of dependent children, and younger households save more because of having fewer siblings to share the responsibility of parental care. These findings lend support to a simple economic model in which the effects of population control policies are investigated in the context of household saving decisions in China.
\end{abstract}

JEL Classification: E21, J11, J13

Keywords: household saving, one-child policy, demographic structure, cohort analysis, China

Corresponding author:

Dennis Tao Yang

Darden School of Business

University of Virginia

Charlottesville, VA 22903

USA

E-mail: YangD@darden.virginia.edu

\footnotetext{
* Dennis Tao Yang would like to thank Jessie Pang for excellent research assistance. The financial support from the Research Grants Council of the Hong Kong Special Administrative Region, China (Project Number 457911) and the research support from the Hong Kong Institute of Asia-Pacific Studies are gratefully acknowledged.
} 


\section{Introduction}

Household saving rate has increased dramatically over the past two decades in China, rising from $16.1 \%$ in 1990 to $21.5 \%$ in 2005 (see Table 1). Behind the rise in average saving rate, the age-saving profile has also evolved into an unusual pattern. In the early 1990s, saving rate was relatively low for young families, and it increased with the age of household heads until they were close to retirement. In recent years, however, household age-saving profiles have turned into a U-shaped pattern, with younger and older households having relatively higher saving rates (see Figure 1A). A more pronounced U-shaped increase in age-specific saving rates is observed from 1990 to 2005 (see Figure 1B), as younger and older households raised their saving rates by over 10 percentage points, much more than middle-aged households. ${ }^{1}$ According to the life cycle theory, young workers save little as they anticipate a rise in future income; the saving rates of middle-aged workers are the highest when their earnings reach the peak; and, saving rates become flat or even decline as workers approach retirement. Such a "hump-shaped" life cycle pattern is often observed in typical cross-sectional analyses in other economies (e.g., Attanasio, 1998; Jappelli and Modigliani, 2005). Recent studies to explain the puzzling U-shaped age-saving profiles in China have focused on factors such as the rising private burden of expenditures on housing, education, and health care (Chamon and Prasad, 2010) and the changes in life cycle earnings profiles and incomplete pension reforms in China (Song and Yang, 2010).

In this paper, we develop and test a new hypothesis that the demographic structural changes resulting from a series of population control policies since the 1970s have contributed to the changes in China's household saving patterns. ${ }^{2}$ After population control policies came into effect, birth rates for successive cohorts plummeted. Consequently, the demographic

\footnotetext{
${ }^{1}$ These findings are based on China's Urban Household Surveys (UHS), which are described in detail in the data section. See Chamon and Prasad (2010), Song and Yang (2010), and Yang, Zhang and Zhou (2012) for systematic documentation of age-specific household saving patterns in urban China.

${ }^{2}$ The demographic transition would also affect other aspects of the economy. See Song et al. (2012) for a recent study on the inter-relationship between China's demographic transition and its economic growth and pension reforms.
} 
structure shifted to a new regime in recent years in which young households have fewer siblings, middle-aged households have fewer dependent children, and old households have fewer adult children. Traditionally, the younger generation is supposed to provide old-age support to their elderly parents in Chinese households. Having fewer siblings, the young households will save more because of the increasing burden of providing upstream transfer to their parents. Households with dependent children can save more with the lighter burden of child care and education expenses. Older people have more incentive to save for old-age security as a substitute for the reduced number of children.

We develop a simple overlapping generation (OLG) model to illustrate how population control policies and demographic structural changes affect saving decisions of individuals at different life stages. Incorporated into the model are key features of the Chinese household structure: parents raise their dependent children; in turn, adult children provide monetary transfers to their elderly parents as old-age support. The model allows parents to be altruistic (treating children as consumption goods) and to use children for old-age support (treating children as investment goods). Population control policies differentially affect the numbers of siblings, dependent children, and adult children for households at different ages (i.e., from different birth cohorts). The model predicts three testable hypotheses following binding birth quota. First, the responsibility of parental care increases for adult children with fewer siblings and their saving rate will increase. Second, households with fewer dependent children will increase their saving because of less mouths to feed. Third, the smaller number of adult children reduces old-age support for parents, thus encouraging the old to save more. These predictions demonstrate how saving decisions of different cohorts respond to demographic structural changes. The behavioral model provides guidance for estimating the relative contributions of various factors behind the changes in age-saving profile in China.

We test the model implications and estimate the effects of demographic structural changes on Chinese household saving using combined data from the Urban Household Surveys (UHS) and population censuses. The UHS contains information on consumption expenditure at 
the household level, but lacks detailed information on fertility histories. Thus, we match the 1989-1991 and the 2004-2006 UHS with the 1990 and 2005 population censuses for each single year-of-birth cohort in each province. The demographic structure experienced dramatic changes from 1990 to 2005 as a consequence of the population control policies and other socioeconomic changes since the early 1970s. For example, compared to their 1990 counterparts, young households headed by those between 26 and 35 years old had 1.9 fewer siblings, middle-aged households headed by individuals in their 40s had 0.3 fewer dependent children, and old households led by those in their 50s had 1.8 fewer adult children in 2005 .

The main empirical challenge in estimating the effects of demographic structural changes on saving is the endogenous nature of fertility decisions. Our identification relies on exogenous variations in cohort-specific fertility generated by the different timing of population control policies that affected different birth cohorts and by the interaction of birth cohorts with fines across provinces on unauthorized births under the one-child policy. Effective implementation of China's population control policies started in the early 1970s. The government tightened population control over time, and eventually the one-child policy was implemented in 1979. Given the timing of the population control policies, cohorts at childbearing ages face downward pressure in fertility, while leaving fertility decisions largely unaffected for previous cohorts. The varying intensity of the policies over time also implies that their impact on fertility differs for successive cohorts affected by the policies. Under the one-child policy, each family is allowed only one child in urban China, and fines are levied on second or higher-parity births. A unique feature of the policy is that the means of implementation and vigor of enforcement of the policy differ across provinces. In particular, the fines on excess birth vary greatly by province and year (Scharping, 2003; Ebenstein, 2010). We exploit the exogenous variability in fertility difference between provinces with different fines for successive cohorts that were exposed to population control policies of varying intensities to facilitate identification. Specifically, we use the interactions of provincial fertility fines with five-year cohort dummies as instruments for the number of children when estimating 
the effects of demographic structural changes on savings. The important observation underlying the identification strategy is that fertility fines may have differential effects on fertility decisions of different birth cohorts with varying fertility history at any given point of time. Note that this identification strategy does not require fertility fines to be exogenous.

Using cohort-level cross-sectional data for 1990 and 2005, we find systematic evidence that demographic structural changes have significant and sizable effects on saving rates. Younger households between 26 and 40 years old increase saving rates by 2.6 to 4.3 percentage points with response to one less sibling. Middle-aged households between 41 and 50 years old save 12.1 to 29.2 percentage points more with one less dependent child. Older households between 51 and 60 years old increase their saving rates by 1.9 to 4.6 percentage points if they have one less adult child. These results confirm the three hypotheses derived from the model. Simple "back-of-the-envelope" calculations based on our point estimates show that the demographic structural changes as measured by variations in the number of siblings, the number of dependent children, and the number of adult children can account for a large portion of the changes in age-saving profile between 1990 and 2005. The rest of the changes can be explained by other socioeconomic factors.

Although numerous studies have attempted to understand the rising household saving in China in recent years, substantial uncertainty remains with regard to the driving forces. Existing research emphasizes the importance of sharp cost increases in health and education (Chamon and Prasad, 2010); competitive saving motive arising from the marriage market (Wei and Zhang, 2011); structural shifts in life-cycle earnings (Song and Yang, 2010); and the constraints of the household registration system (Chen, Lu and Zhong, 2012). Given the dramatic changes in demographic structure, the existence of little empirical evidence on its relationship with household age-saving profile is somewhat surprising. Several studies attempt to investigate the link between demographic structure and household saving at the aggregate level (Modigliani and Cao, 2004; Horioka and Wan, 2007; Curtis, Lugauer, and Mark, 2011). Using household data, Banerjee, Meng, and Qian (2010) investigate the 
effects of fertility and child gender on parents' saving decisions. They use a sample of households headed by individuals between 51 and 65 years old, and therefore only study the saving behavior of old households. Instead, we show that fertility influences saving behavior differently for households at various stages of their life cycle. Aside from previous studies, we highlight how age-specific saving decisions respond to demographic structural changes, and investigate the shift of the entire age-saving profile over time.

The rest of this paper is organized as follows. Section 2 briefly describes the evolution of China's population policies and their impact on demographic structure. Section 3 presents a simple OLG model that links population control policy, demographic structural change, and household saving. The model provides a framework to specify and interpret our empirical results. Section 4 describes the data and variables. Section 5 discusses the empirical strategy and presents the results on the effects of demographic changes on household saving rates by age. Section 6 concludes.

\section{Population Control Policies in China}

China has witnessed major changes in its population policies over the past few decades, moving from encouraging population growth to strictly enforcing population control. In the early 1950s, Chinese families were encouraged to have children. The population rose from 550 million in 1950 to 830 million by 1970 . The rapid population growth during the 1950s and 1960s led to the "Wan (Later), Xi (Longer), Shao (Fewer)" campaign of the 1970s. This policy called for later marriage and child bearing, wider spacing between births, and fewer children. Education, propaganda, and persuasion were the officially stated means of policy implementation (Yang and Chen, 2004). Men were encouraged to marry no earlier than 28 years old and women no earlier than 25 years old. Couples were persuaded to allow at least a four-year gap after the first child before having another baby. Urban families were also suggested to limit their number of children to two. The total fertility rate plummeted from 
close to 6 in 1970 to less than 3 by the end of the 1970s (Coale, 1984).

However, population growth remained high; the baby boomers of the 1950s and 1960s were entering their reproductive years, and by 1979, approximately two-thirds of the population were under 30 years old. When economic reform was launched in the late 1970s, the government considered curbing population growth as essential to economic expansion and to an improvement in the standard of living. In 1979, the authorities tightened their population control and introduced the one-child policy, which allows each household to have only one child. Households were given birth quotas, and "above-quota" births were penalized. This policy aimed to limit China's population to 1.2 billion by 2000. After the implementation of the one-child policy, the total fertility rate declined gradually from just below 3 in 1979 until 1995, and then more or less stabilized at approximately 1.7 (Hesketh, Lu and Zhu 2005).

Despite its name, the one-child rule does not equally apply to all Chinese families. Ethnic minorities are initially excluded from the policy. ${ }^{3}$ For urban residents and government employees of Han ethnicity, the one-child policy is strictly enforced, with few exceptions. If both parents are only children, they are allowed to have more than one child provided that the birth spacing of children is more than four years. Families in which the first child has a mental or physical disability or both parents work in high-risk occupations (i.e., mining) are allowed to have another child. ${ }^{4}$

The State Family Planning Bureau sets the overall population control targets and policy direction. However, the implementation of the policy varies from one locale to another. Family-planning committees at the provincial and county levels devise local strategies for implementing the state policy of population control, under the general principle of one child per couple. Residents of different provinces are subject to different birth limits permitted

\footnotetext{
${ }^{3}$ China officially recognizes 56 distinct ethnic groups, with Han Chinese being the largest and comprising approximately $92 \%$ of the total population. See Li and Zhang (2009) for details on the one-child policy applied to ethnic minorities.

${ }^{4}$ Our discussion of the population control policies has focused on urban areas as our empirical analysis is based on an urban sample. Population control is generally less strict in rural areas. For example, in rural areas, a second child is allowed after five years, but this provision sometimes applies only if the first child is a girl - in recognition of the traditional preference for boys and the reality in rural areas of the need for male labor.
} 
by the local policy (Gu et al. 2007). Economic incentives are provided for compliance, and noncompliance leads to substantial fines and possibly other nonfinancial penalties. Various studies have shown that these fines are heavy and vary enormously across provinces. The fines range from $20 \%$ to $200 \%$ of a household's annual income (Short and Zhai 1998; Ebenstein 2010). Even at the lower end of the range, the fines are still substantial.

The rapid decrease in birth rate, combined with improving life expectancy, has led to a significant change in the age structure of the Chinese population. ${ }^{5}$ The decline in child dependency ratio (defined as the ratio between the children population aged 14 years or below and the working-age population between 15 and 64 years, expressed in \%) and rise in old-age dependency ratio (defined as the ratio between the population aged 65 years or above and the working-age population, expressed in \%) are the major trends in China's demographic structure (Figure 2). We further plot the more detailed population structure change (United Nations, 2008) in Figure 3. In 1970, the population structure was a pyramid with a large base of young people. The number of children declined significantly over time due to the sequence of population control policies. More relevant to this study, we observe a clear regime shift of population age structure between 1990 and 2010. The proportion of the population between 50 and 60 years old was $7 \%$ in 1990 and stood at $12 \%$ in 2010, and these age cohorts experienced a rapid fertility decline as shown by the shrinking size of young workers in their $20 \mathrm{~s}$ and early $30 \mathrm{~s}$. The proportion of the middle-aged between 40 and 50 years old increased from $10 \%$ in 1990 to $16 \%$ in 2010, whereas their children's generation reduced in size. The proportion of the population below the age of 15 years was $28 \%$ in 1990 and dropped to $20 \%$ in 2010 . In Chinese tradition, children are the source of old-age support. The fertility decline induced by the population control policies has severely curtailed this tradition.

\footnotetext{
${ }^{5}$ Another outcome of family planning was an increase in the male-female ratio in China (Ebenstein 2010; Li, Yi and Zhang, 2011).
} 


\section{A Simple Theoretical Framework}

We postulate that China's population control policies and demographic shifts have had a profound impact on household saving behavior over the lifetime. One major difficulty in assessing these impacts is that, concurrently with the implementation of family planning programs and the demographic transition since the early 1970s, fundamental socioeconomic changes have occurred in China. The rising household saving took place against the backdrop of China's transition to a market economy and rapid income growth. Institutional reforms have occurred whereby health care systems, education finance, pension arrangement, and other social welfare provisions have evolved with the transition to a market economy. Other elements, such as the rising household income, increasing overall macroeconomic uncertainty, housing reform, and rising housing price, occurred during the same period, and likely have affected household saving behavior.

In this section, we present a simple OLG model to focus on the effects of population policies and demographic changes by holding other socioeconomic variables constant. The model is useful in justifying the empirical specification we use and in interpreting the empirical results. According to the model, changes in population control policies have different effects on saving rates for individuals at different points in their lifetime. We will make these relationships precise in the model and form our empirical specification based on them. In the empirical analysis, we will also consider the effects of other socioeconomic variables aside from the demographic shifts induced by population control policies.

\subsection{The Model}

The economy is populated with overlapping generations, referred to as the children, the school-aged youth, the young, middle-aged and old workers, and the retired. We assume that people start making economic decisions when they become young workers. In each of the working-age periods, all workers supply one unit of labor inelastically. Let the socioeconomic 
environment and the information set available be denoted by $\psi$. The after-tax earnings of the young, middle-aged, and old workers are denoted by $y_{1}, y_{2}$, and $y_{3}$, respectively. When people retire, they receive the pension benefits of $y_{4}$.

A generic individual has children when young. Each individual has a utility function, $u(c, f)$, and extracts positive utility from both consumption $(c)$ and quantity of children $(f)$. For simplicity, we do not consider the quality of children. Given the socioeconomic environment, preferences for a young worker are represented by

$$
\sum_{i=1}^{4} \beta^{i-1} u\left(c_{i}, f ; \psi\right)
$$

where $\beta$ denotes the discount factor, and $c_{i}$ stands for consumption of an individual of age $i$ ( $i=1,2,3$ refers to the three working ages, respectively, and $i=4$ refers to retirement). In the empirical analysis, we will focus on the behaviors of working-age individuals between 26 and 60 years old. Almost all individuals have completed formal schooling by age 26, and by age 60, all Chinese workers are officially retired.

The model allows parents to be altruistic, and they pay $q$ to raise each child. The cost of children incurs over time from a child's birth to school age, until the child becomes a working young adult. In the model, people have children when they are young adults; as the children grow into school age, the parents are in their middle age. For illustration purpose, we assume that the middle-aged parents pay the cost $q$ for their school-aged children. The child cost $q$ includes household expenditure on children in terms of food, clothes, and shelter, the opportunity cost in terms of parental time, and schooling expenses.

Following the Chinese tradition, parents also use children for old-age support. We assume that there exists a targeted level of old-age support for parent, $R$, equally shared by all adult children. Adult children are expected to take care of their elderly parents after retirement as long as they are around. Given that early retirement starts at around age $50,{ }^{6}$ we assume

\footnotetext{
${ }^{6}$ The official retirement age is 50 for women in blue-collar jobs, 55 for other women, and 60 for men. Disabled workers may retire ten years earlier, and workers from bankrupt state-owned enterprises may retire five years earlier.
} 
that a young adult pays his/her share of parental support $R / n^{s}$ to the old parent, where $n^{s}$ is the number of siblings (including oneself). If no uncertainty arises and every child pays his/her share, an old parent receives a transfer of $R$ from all the children. Figure 4 presents the time line of inter-generational transfers.

Although almost all parents would pay to raise their dependent children, the old-age support paid to elderly parents follows social norm and is rather voluntary. If some adult children do not pay for their parents' old-age support because of mortality risk, financial difficulty, or in defiance of tradition, the likelihood to secure old-age support from adult children would increase with the number of children. That is, the old-age support $R$ becomes an increasing function of the number of adult children, or $R^{\prime}(f)>0$. Furthermore, we assume that each adult child's share of parental care, $R(f) / f$, decreases in the total number of children.

Therefore, a young worker chooses the optimal saving decision by maximizing lifetime utility subject to the following inter-temporal budget constraint:

$$
c_{1}+\frac{R\left(n^{s}\right)}{n^{s}}+\frac{c_{2}+f q}{1+r}+\sum_{i=3}^{4} \frac{c_{i}}{(1+r)^{i-1}}=\sum_{i=1}^{4} \frac{y_{i}}{(1+r)^{i-1}}+\frac{R(f)}{(1+r)^{2}}
$$

where $r$ is the interest rate. The fertility variable $f$ represents both the number of dependent children for the middle-aged households and the number of adult children for the old households.

Assuming log utility in consumption and separability in consumption and number of children, the saving decision of the young solves

$$
\max \sum_{i=1}^{4} \beta^{i-1} \log c_{i}(\psi)+\lambda G[f(\psi)]
$$

subject to the budget constraint (2). Children enter parents' utility through function $G(\cdot)$, and the parameter $\lambda$ measures the degree parents care about their children. The parameter $\psi$ represents the socioeconomic environment determined outside the model. 
The Euler equation implies the following consumption pattern over the lifetime,

$$
c_{1}(\psi)=\frac{c_{2}(\psi)}{\beta(1+r)}=\frac{c_{3}(\psi)}{\beta^{2}(1+r)^{2}}=\frac{c_{4}(\psi)}{\beta^{3}(1+r)^{3}} .
$$

If fertility is optimally chosen, then the optimal number of children $f^{*}$, given $\psi$, satisfies

$$
\rho \frac{q(1+r)-R^{\prime}\left[f^{*}(\psi)\right]}{\lambda(1+r)^{2} G^{\prime}\left[f^{*}(\psi)\right]}+\frac{f^{*}(\psi) q}{1+r}=\sum_{i=1}^{4} \frac{y_{i}}{(1+r)^{i-1}}+T\left(f^{*}, n^{s}\right)
$$

where $\rho=1+\beta+\beta^{2}+\beta^{3}$, and the term $T\left(f^{*}, n^{s}\right)=R\left[f^{*}(\psi)\right] /(1+r)^{2}-R\left(n^{s}\right) / n^{s}$ measures each individual's net gains through inter-generational transfers of old-age support. Positive $T$ implies net positive transfer from children, whereas negative $T$ implies net transfer to parents. Transfers from children increase in the number of adult children, and the burden of parental support decreases in the number of siblings. Thus, the net gain $T$ increases both in the number of adult children and the number of siblings.

It is easy to show that saving rate when young equals

$$
s_{1}(\psi)=\frac{y_{1}-c_{1}}{y_{1}}=1-\frac{1}{\rho} \times\left[\sum_{i=1}^{4} \frac{y_{i}}{y_{1}(1+r)^{i-1}}-\frac{f^{*}(\psi) q}{y_{1}(1+r)}+\frac{T\left(f^{*}, n^{s}\right)}{y_{1}}\right]
$$

For a young individual, the saving plan for the middle-aged and old periods are given by

$$
\begin{aligned}
s_{2}(\psi) & =\frac{y_{2}-c_{2}-f^{*}(\psi) q}{y_{2}} \\
& =1-\frac{\beta}{\rho} \times\left[\sum_{i=1}^{4} \frac{y_{i}}{y_{2}(1+r)^{i-2}}+\frac{\left(1+\beta^{2}+\beta^{3}\right) f^{*}(\psi) q}{\beta y_{2}}+\frac{T\left(f^{*}, n^{s}\right)(1+r)}{y_{2}}\right] ; \\
s_{3}(\psi) & =\frac{y_{3}-c_{3}}{y_{3}} \\
& =1-\frac{\beta^{2}}{\rho} \times\left[\sum_{i=1}^{4} \frac{y_{i}}{y_{3}(1+r)^{i-3}}-\frac{(1+r) f^{*}(\psi) q}{y_{3}}+\frac{T\left(f^{*}, n^{s}\right)(1+r)^{2}}{y_{3}}\right] .
\end{aligned}
$$

In the initial equilibrium, no population control policy exists, and the socioeconomic environment is fixed at $\psi$. Equations (4) to (6) present household saving rates over the life cycle. 
If we further assume that all households face the same life-cycle earning profile, interest rate and discount rate, then Equations (4) to (6) also illustrate the age-saving profile for a cross-section of households at a steady state equilibrium.

In our empirical work, we look at a cross section of individuals at different life stages. There are two ways to interpret the life cycle decision of Equations (4) to (6) of a given individual in a cross-sectional context. The first way is to assume that different birth cohorts have the same $\psi$ (which does seem unrealistic). At a given point of time, Equations (4), (5), and (6) would apply to the young, middle-aged, and old households, respectively. Thus, a change in $\psi$ will have different effects on individuals of different cohorts. The second way is to assume that different birth cohorts have different $\psi$. Then, again, Equations (4), (5), and (6) would correspond to the young, middle-aged, and old households, respectively. Any change in $\psi$ will have more different effects on individuals of different cohorts than under the first interpretation. Either way, Equations (4) to (6) imply that population policies would have different effects on individuals of different birth cohorts and that the resulting demographic structural changes would also have different effects on individuals at different life stages at a given point of time. The age-specific effects of demographic structural changes will be further discussed in the next section.

\subsection{Population Control Policies}

In the context of household saving decisions in China in the past two decades, households face many uncertainties against the backdrop of China's transition to a market economy and rapid income growth. For example, the socioeconomic environment and demographic structure have both changed dramatically over time. These shocks will shift the saving profile over time. We are particularly interested in the impact of demographic changes caused by population control policy on saving rates.

Suppose the state population policy set the maximum number of children each couple

can have at $\bar{f}$ and $\bar{f}<f^{*}$. Given the binding birth quota, households make constrained 
optimization by setting $f=\bar{f}$. Initially, households that had passed childbearing age were unaffected by the policy. For those influenced by the policy, the policy might come as a surprise. For instance, a 26-year-old woman in 1977 did not anticipate the one-child policy and made a lifetime saving decision based on her optimal fertility rate, say $f^{*}=2$. At age 28 , the one-child policy was implemented, such that each family has a birth quota of $\bar{f}=1$. If the household had not reached its optimum of two children, it would reoptimize at age 28 given the accumulated asset at age 27. The marginal effects of fertility reduction on saving generated by an unanticipated change in population policy are different from those generated by the same but anticipated change in the policy.

Eventually, the economy will converge to a new steady state equilibrium in which all individuals are exposed to the population control policy and fully anticipate the fertility constraint. At this equilibrium, the consumption pattern of the households still follows Equation (3). Optimal consumption over lifetime can be solved by combining the budget constraint (2) and first-order conditions (3). The saving rates for households of different ages are determined by Equations (4) to (6) by replacing $f^{*}$ and $n^{s}$ with $\bar{f}$, when lifetime earnings and other socioeconomic variables are held constant. As Equations (4) to (6) show, changes in the number of children or the number of siblings induced by the population policy have different effects on the saving rates of individuals at different points of their lifetime.

It takes a few decades for all birth cohorts in an economy to be fully exposed to the population control policy and reach constrained optimization. A more relevant analysis for our purpose is to consider how households of different ages have responded to the implementation of the population control policies since the early 1970s. Specifically, we focus on three age groups in 2005, and investigate how these three age cohorts' saving behavior changes relative to the benchmark steady state equilibrium without family planning.

For the old households in 2005, their number of siblings is unaffected by the population control policies. As the number of children $(f)$ goes down, as shown in Equation (6), two opposing effects on their saving exist. The first effect is the substitution between old-age 
support from adult children and own saving. When people have fewer adult children, the net transfer $T$ goes down and precautionary saving is induced because of old-age security concerns. The possibility that the precautionary motive induced by the reduced number of adult children could interact with other uncertainty also arises. For example, if public pension is reduced, people will rely more on private saving or children's old-age support for retirement. In this case, the reduced old-age support due to fewer adult children may induce even more private savings. On the other hand, an indirect effect of the number of children on the saving of old households emerges. These households had fewer dependent children to support when they were younger. As expenditure on dependent children decreases, more income is available for consumption over the lifetime. Therefore consumption expenditure increases and people save less, as the second term in the bracket in Equation (6) shows. Although the effect of fertility decline on old households' saving is theoretically ambiguous, we postulate that the old-age security effect dominates, especially when the number of adult children is considered. This assumption leads to the following hypothesis.

Hypothesis 1: As the number of adult children decreases, old households will save more for the purpose of old-age security.

For the middle-aged households in 2005, their number of siblings is also unaffected by the population policies. After the implementation of the population control policies, these households have fewer dependent children and less mouths to feed. Thus, they can spend less on children and save more, as shown by replacing $f^{*}$ with $\bar{f}$ in the second term in the bracket in Equation (5). The number of mouths to feed effect should apply to any household with dependent children. This inference leads to the second hypothesis derived from the model that can be tested empirically.

Hypothesis 2: As the number of children decreases, middle-aged households with dependent children to support will increase their saving because of less mouths to feed.

Younger households in 2005 are not only subject to the birth quota, but their parents' 
fertility decisions are also likely affected by the population control policies. Thus, they have a smaller number of siblings compared to the birth cohorts in the benchmark steady state equilibrium. In Equation (4), as $n^{s}$ declines, each person's burden of parental care increases and the net transfer from children $T\left(f, n^{s}\right)$ goes down. Therefore, individuals will consume less and save more.

Hypothesis 3: As the number of siblings decreases, young households will save more to provide old-age support to parents.

Concurrently with the implementations of population control programs, China has undergone profound socioeconomic changes. The simple model presented in this section takes all of them as given and focuses on the effects of population policies on household savings. In the empirical analysis, we will try to make them explicit.

\section{Data}

Our empirical analysis aims to test the hypotheses postulated in the model and assess the effects of population control policies and demographic structural changes on household saving. A data set suited to our purpose should contain the following information: first, accurate measures of household saving rates for multiple years; second, cohort-specific data on family composition, including complete information on the numbers of adult children, dependent children, and siblings for successive cohorts; third, good measures of time or regional variations in population control policies; and fourth, other household demographic information and socioeconomic variables that may affect saving decision. To fulfill the data requirement on saving rates, we need repeated household income and expenditure surveys. Although household surveys often have rich demographic information, they are typically residencybased; thus, a household member is observed only if the person lives with the household head. The majority of adult children and some dependent children in post-secondary school do not live with parents, and adult siblings typically live in separate households. Therefore, 
inferring the complete family composition information that fits our need at the household level is not possible. The household sample alone is insufficient to test the model hypotheses.

Our strategy is to construct a cohort-based sample that meets all data requirements using multiple data sources. The saving data we use come from the UHS conducted by China's National Bureau of Statistics (NBS). The UHS is an on-going income and expenditure survey of Chinese urban households, and it is known to be the best micro data on household saving in China. The survey also records detailed information on employment, wages, and demographic characteristics of all household members in each calendar year. The second main data source is the Chinese population censuses. The censuses contain the most comprehensive demographic information of Chinese households and provide information on the family composition of different cohorts. We match them with the saving information of the same cohorts from the UHS. We likewise collect province- and time-specific fine/income ratio, which is the ratio between above-quota fertility fines and annual household income under the one-child policy, as a measure for the strictness of the population control policy. We also collect other socioeconomic variables that may affect household saving from various sources. The strength of our cohort-based sample is that it not only combines the best available household saving data with the most comprehensive demographic information, but also contains policy variations that facilitate identification.

For the current analysis, we use UHS data from six provinces that are broadly representative of China's rich regional variation, namely, Beijing, Liaoning, Zhejiang, Sichuan, Guangdong, and Shaanxi. Beijing is the rapidly growing capital city in the north; Guangdong and Zhejiang are dynamic high-growth provinces in the south coastal region; Liaoning is a heavy-industry province in the northeast; and Sichuan and Shaanxi are relatively less developed inland provinces located in the southwest and northwest, respectively. In the UHS, each household reports data on expenditure on different commodities. We construct a standard measure of household consumption that includes expenditure on goods and services (including rent), interest payments on mortgages, vehicle loans and other loans, cash 
contributions to organizations, and insurance premiums. We have also considered alternative consumption measures that exclude various items, which might be considered as saving. Specifically, we first exclude expenditure on durables, then on health and education, which can be considered as investment in human capital, and finally on mortgage payments. Income is defined as total disposable family income, which includes earnings, transfers, capital income, and pensions net of all income taxes and social security contributions. Saving is defined as the difference between disposable income and consumption. ${ }^{7}$ Saving rates are computed as the ratio of saving to income. Using alternative household consumption measures causes no major changes to the facts documented below, except for saving rates after retirement. Saving rates after retirement are not quantitatively important; hence, throughout the paper, we shall focus on the saving behavior of working-age households with household head age between 26 and 55 (for female) or 60 (for male).

We use UHS data to construct household age-saving profiles for 1990 and 2005. Given the limited sample size, we combine the observations from the 1989-1991 surveys as representing 1990 and similarly, observations from 2004-2006 as representing 2005. An age-specific saving rate is derived from averaging household saving rates for all households with the same age in each period. Panel A of Figure 1 presents age-saving profiles for the two periods. Considering that some age cells contain few observations, we use three-age moving average to minimize the effect of measurement error. In the 1989-1991 period, the saving rates are relatively flat before age 40 and then increase toward the retirement age. For the 2004-2006 period, agesaving profile exhibits a dramatic change: it turns to a U-shape. Using alternative saving definitions results in a qualitatively similar U-shaped profile. We further eliminate fixed life-cycle effects by taking the difference of the two profiles. The outcome yields the increase

\footnotetext{
${ }^{7}$ The saving definition we adopt treats social security contribution as taxes, but this contribution can also be recognized as mandatory life-cycle saving (Jappelli and Modigliani, 2003). We are unable to construct a consistent saving measure including social security contribution because no information is available for social security contribution in the 1989-1991 UHS. For the 2004-2006 period, households on average contribute $5.2 \%$ to $8.4 \%$ of the household income to social security, with households between age 41 and 50 making the highest contribution. Therefore the 2004-2006 age-saving profile in Figure 1A would be higher and the U-shape slightly less pronounced if social security contribution is included.
} 
in saving rates by age from 1989-1991 to 2004-2006, as depicted in panel B of Figure 1 . The U-shaped pattern becomes more pronounced: the average increase of saving rates for those aged below 40 and above 50 is equal to 10.7 and 7.6 percentage points, respectively, whereas that for those between 40 and 50 years old is only 3.5 percentage points. The rise in the saving rates of the young and the old among working-age households sharply contrasts with the typical hump-shaped or relatively flat age-saving profile. ${ }^{8}$

Each age cohort between 26 and 60 in 1990 and 2005 corresponds to a birth cohort born between 1930 and 1979. These age cohorts have had different exposure under China's population policies over time. Among them, the older ones born in the 1930s had children in the 1950s and 1960s when no population control policy was implemented; those born in the 1940s and early 1950s experienced the "Later, Longer, Fewer" family planning program in the 1970s; those born in the late 1950s and onwards were all subject to the one-child policy at their childbearing age; finally, the youngest cohort was likely born as the only child in the family. To construct the cohort-specific family composition and demographic structure variables, potentially affected by the population control policies, we match the 1989-1991 and 2004-2006 UHS households with the 1990 population census and the $20051 \%$ census. We use the census urban samples in the corresponding six provinces to be consistent with the households from the UHS. In the censuses, all women between age 15 and 64 report the number of children ever born to them, and each person in a household can be identified. We consider three demographic variables that are investigated in the model and affected by population policies. First, we construct a variable on cohort-specific average number of children ever born, for households of each age between 26 and 60 in 1990 and 2005 and in each province. Saving data from UHS are collected based on the age of the household head, but fertility information from census is for women. The number of children is therefore computed as a weighted average using the gender and marital status distribution of household heads. ${ }^{9}$

\footnotetext{
${ }^{8}$ For subsamples classified by household head's education and gender, they also feature a U-shaped level in 2005, as well as a U-shaped increase of saving profile.

${ }^{9}$ In particular, consider all household heads at age $a$ in year $t$, and let $j$ denote household type, such that $j=1$ corresponds to single male, and $j=2,3,4$ corresponds to married male, single female, and married
} 
In the empirical analysis, we use this variable as a proxy for the number of adult children. Second, we create a variable on the number of dependent children. Dependent children are defined as children aged below 15 and those above age 15 but are still attending school. We count the number of dependent children each household has and compute the average conditional on the household head's age. Finally, we investigate the number of siblings each age cohort has. Although we have information on how many children people have from the population censuses, information on the number of siblings is unavailable. We proxy the number of siblings by locating their parents' birth cohort and collecting information on its number of children. ${ }^{10}$

Panel A of Figure 5 presents the age-specific average number of children ever born from the 1990 and 2005 censuses. In 1990, the young households between 26 and 35 years old on average have one child. They were below age 24 in 1979 when the one-child policy was first implemented, and therefore were constrained by the policy. Those over age 35 have more children because the corresponding birth cohorts have had children or passed their childbearing ages when the one-child policy was imposed. The increase in the number of children by age reflects both the cumulative fertility effect over the life cycle and the declining fertility rate over time since the mid-1960s, under various population control policies. In 2005, the age profile shows a dramatic change: the number of children hovers around one for all households between 26 and 50 years old, and then it increases and reaches less than three at the age of 60 . This pattern is closely related to the population control policies. Those aged between 26 and 50 in the 2005 census were all younger than 24 when the one-child

female, respectively. We first compute the proportions of households given the heads' gender and marital status $P_{a, t}^{j}$. From the censuses, women of all ages report the number of children ever born, and therefore we have fertility information for all female cohorts $F_{a, t}^{j}$ with $j=3,4$. Now assume single men have no children. Men tend to marry younger women, and we identify the average age of women, $a^{\prime}$, married to men at age $a$ in year $t$. The weighted fertility for age cohort $a$ at time $t$ in our sample is then computed as $P_{a, t}^{2} F_{a^{\prime}, t}^{4}+P_{a, t}^{3} F_{a, t}^{3}+P_{a, t}^{4} F_{a, t}^{4}$.

${ }^{10}$ For example, those who were 40 years old in 2005 were born in 1965 . Suppose on average their parents gave birth at the age of 25, then their parents belong to the 1940 birth cohort. We use the average fertility rates of 50-year-old individuals in 1990, who were born in 1940, as proxy for the number of siblings for the 1965 birth cohort. We use the 1982, 1990, and 2005 censuses to construct the variable on the number of siblings. 
policy was imposed, and therefore subject to the birth quota. We further eliminate fixed life-cycle effects by taking the difference of the two profiles. The outcome yields the decline in the number of children over age from 1990 to 2005, as depicted in panel B of Figure 5. Households of all ages have fewer children in 2005, but the change is much more pronounced for the older households. The average decline for those aged between 26 and 35 is 0.15 children. The decline increases in age, and by age 50, households in 2005 on average have two fewer children compared to the 1990 households. If parents rely on adult children for old-age support, the decrease in the number of children will have a larger effect on older households.

In Figure 6, we present the changes in the number of dependent children from 1990 to 2005. Panel A shows that the age profile of dependent children is hump-shaped. The number of dependent children increases with the age of household heads, reaches the peak at around age 40, and then declines as children enter adulthood and leave the household. The age profile of 2005 is lower than that of 1990 as fertility rate declines. As panel B of Figure 6 presents, for those between 26 and 40 years old, the 2005 households have on average 0.5 fewer dependent children compared to the 1990 households. Given that these households have fewer dependent children to raise, they are likely to save more. For older households, changes in the number of dependent children from 1990 to 2005 are much smaller.

Old-age support to the parents is typically shared among siblings. Therefore, one's responsibility for parental care depends on his/her number of siblings. Panel A of Figure 7 presents the age-specific average number of siblings (including oneself) in 1990 and 2005. Even the very young households in 1990 were born in the 1960s, before the implementation of population control policies. Young households between 26 and 35 years old had just below four siblings, whereas older households had slightly more than four siblings. In 2005, household heads belong to much younger birth cohorts, and were born between 1945 and 1979. Although the one-child policy had little effects on them, they experienced a dramatic demographic transition in the 1970s due to the "Later, Longer, Fewer" campaign and other 
socioeconomic changes. The average number of siblings increased from just above one to more than four across age cohorts. Panel B of Figure 7 plots the changes in the number of siblings by age from 1990 to 2005 . Consistent with declining fertility rates, the number of siblings decreased by around two for the very young households. The changes over time are much smaller for older households, and for those aged 50 and above, the number of siblings barely changes.

Combining household age-specific saving data from the UHS and the demographic information of the corresponding birth cohorts from censuses, we have constructed a unique data set based on age cohorts. We also explore the geographic variations in saving and demographic structural change. Average saving rates are computed for all households with the same age between 26 and 60 years old in 1990 or 2005, located in one of the six provinces. Accordingly, demographic variables including the number of children ever born, the number of dependent children, and the number of siblings are constructed for the corresponding age cohorts in each time period and province. We also consider other variables that may affect household saving. For each age cohort in the sample, we construct variables on demographic characteristics, such as the proportion of people having high school or above education, the proportion of minorities, and the proportion of state employees. Following Wei and Zhang (2011), we use the local sex ratio for age cohorts between 7 and 21 to measure the competitiveness of the marriage market. The other province- and time-specific socioeconomic variable we consider is the government spending on social security per person, taken from the statistical yearbooks. Finally, under the one-child policy, the strictness of the policy can be measured by province- and time-specific fine/income ratio for unauthorized births. This aspect provides an important source of variation for the demographic structural change. The fine/income ratio is the ratio between above-quota fertility fines and annual household income, taken from Ebenstein (2010).

Summary statistics are presented in Table 1 . The sample consists of 416 observations, ${ }^{11}$

\footnotetext{
${ }^{11}$ We have data for 35 age cohorts (between age 26 and 60) in two years and in six provinces $(35 \times 2 \times 6=420)$. Four observations are missing because saving rates are not observed for the corresponding
} 
with an average saving rate increasing from $16.07 \%$ to $21.47 \%$. As a result of the population control policies and demographic transition, the average number of children declined from 1.99 to 1.22 between 1990 and 2005, the average number of dependent children dropped from 0.57 to 0.40 , and the average number of siblings decreased from 4.01 to 3.17 during the same time period. Between 1990 and 2005, the average working-age households became much more educated, with high school completion rate increasing from $36.8 \%$ to $52.9 \%$. The proportion of minorities increased from $2.4 \%$ to $3.6 \%$, and the share of state employment dropped from $81.0 \%$ to $46.6 \%$. The sex ratio increased from 104 in 1990 to 113 in 2005, reflecting an increasing sex imbalance in China in recent decades. Government spending on social security per person has also increased over time. Average fertility fines increased from 1.24 times of annual household income in 1990 to 3.25 times of annual household income in 2005.

\section{Empirical Analysis}

Our model provides useful guidance to formulate our empirical specifications, develop an identification strategy, and help interpret our empirical findings. Although we mainly investigate the linkages between demographic changes and household saving, we will also incorporate other socioeconomic determinants of saving postulated in the literature into our empirical framework.

\subsection{Empirical Specifications}

Based on the three hypotheses previously discussed, we model saving rates as a function of the number of adult children, the number of dependent children, and the number of siblings to capture the effects of demographic structure on savings. As we have shown in the behavioral model, changes in demographic structure have different effects on households' saving rates age, year, and province combinations. 
at different points in their lifetime. Therefore, the effects of demographic variables on saving are age-dependent. In the most flexible specification, we may allow these variables to have interactions with all ages between 26 and 60 in the saving equation. This specification, however, is hardly feasible given the small size of our cohort-based sample. Instead, we define seven age-interval dummies $(i=1,2, \ldots, 7)$ corresponding to ages between 26-30, 31$35, \ldots, 56-60$, by assuming that the effects of the three demographic variables on savings are the same within each five-year age interval, but vary across age intervals.

We specify the following saving equation with the interactions of all demographic variables with age-interval dummies,

$$
\begin{aligned}
S_{a, j, t}= & \alpha_{0}+\sum_{i=5}^{7} \beta_{i} I(a=i) F_{a, j, t}+\sum_{i=3}^{5} \gamma_{i} I(a=i) D_{a, j, t}+\sum_{i=1}^{3} \delta_{i} I(a=i) N_{a, j, t}^{s} \\
& +\alpha_{1} a g e+\alpha_{2} a g e^{2}+\mathbf{X}_{a, j, t} \boldsymbol{\theta}+u_{t}+v_{j}+\varepsilon_{a, j, t},
\end{aligned}
$$

where $S_{a, j, t}$ is the average saving rate for households with household head of age $a$ in province $j$ at time $t . F_{a, j, t}$ and $D_{a, j, t}$ are the numbers of adult children and dependent children that these households have, respectively. $N_{a, j, t}^{s}$ is the number of siblings. The seven age-interval dummies $(i=1,2, \ldots, 7)$ correspond to five-year age intervals between $26-30,31-35, \ldots, 56-$ 60 , and $I(\cdot)$ is an indicator function that equals one if households' age $a$ lies within interval $i$ and zero otherwise. The coefficients $\beta_{i}, \gamma_{i}$, and $\delta_{i}$ thus estimate the age-specific effects of demographic structure on household saving. Age and age squared control for life-cycle saving effects. $\mathbf{X}$ is a vector of other control variables. To capture macroeconomic shocks, we allow for a year dummy, $u_{t}$. The year dummy may also capture the effects of changing costs of children and old-age support over time on saving. We use province dummies $v_{j}$ to capture time-invariant and province-specific effects. These additional control variables relax the theoretical model assumption that socioeconomic environment $(\psi)$ is fixed over time.

In the saving equation (7), instead of allowing demographic variables to have interactions with all age-interval dummies, we restrict our attention to selected age intervals for each 
demographic variable. This specification is mostly based on the empirical revelation of individual behavior and various specification tests. Young workers may worry little about their own old-age security, and they may not have complete information about the total number of children they will have eventually. When they are approaching retirement age, the old-age security concern based on the number of adult children starts mounting. Therefore, the number of children effect due to old-age security is most relevant for older households, and thus we consider the interactions of the number of children with age dummies between 46 and $60 .{ }^{12}$ On the other hand, the number of mouths to feed effect only exists for households with dependent children. For those above 50, their children have already become young adults; therefore, no dependent children effect on saving decision should emerge. Thus, we consider the interactions of dependent children with age dummies between 36 and 50 as they are young enough to have dependent children. ${ }^{13}$ Concern about old-age support of parents should be most relevant for younger households. The reason is that many of the parents of those aged above 45 have passed away. ${ }^{14}$ Therefore, we include the interactions of the number of siblings with age dummies between 26 and 40 because their parents are either close to retirement or have retired, but are still around. To relax the assumptions on the exact age cutoffs, we have experimented with one or two additional age-interval interactions with all demographic variables. The additional interaction terms all have insignificant coefficients, and they do not affect our main results. These results are available from the authors upon request. ${ }^{15}$

\footnotetext{
${ }^{12}$ Given the timing of the population control policies, the number of children that young households have barely changed from 1990 to 2005 as shown in Figure 5. Thus, the rise in precautionary saving for old-age security induced by fewer children should be most relevant for the older households.

${ }^{13}$ The cost of raising children is relatively low before they go to high school because of the nine-year compulsory public school system. After nine years, education costs increase, especially for college education. We have attempted to include the interactions between dependent children and age intervals 26 to 30 and 31 to 35 , but both coefficients are statistically insignificant.

${ }^{14}$ Life expectancy was 68.6 years in 1990 and 71.4 years in 2000 (China Statistical Year Book 2005, NBS).

${ }^{15}$ Another concern on the specification with full age-interval interactions is that the number of children ever born is highly correlated with the number of dependent children for households below age 45; however, as children become adults and leave home, these two variables become more distinguishable.
} 


\section{$5.2 \quad$ Identification Strategy}

The estimation of Equation (7) on Chinese data poses a number of challenges. The main challenge is the possibility that individual (and unobserved) heterogeneity in saving behavior is related to the fertility decision. For example, if more frugal households save more and have systematically fewer children, the OLS estimates of the coefficient on the number of children in cross-sectional studies will be downward biased. On the other hand, a shortcoming of studies that rely on time-series variation is that fertility generally trended down since the mid-1960s, whereas saving trended up. From a simple time-series study, determining whether the negative relationship between fertility and saving is causal or due to some other variables that have also trended over time is difficult.

Another concern on our specifications is that the migration of households across provinces could bias the estimates. For example, suppose we observe the saving rate and the number of siblings of 30-year-old individuals in Zhejiang in 1990. If they were instead born in the province of Guangdong, our estimates are biased because the relevant number of siblings is that of Guangdong province. Prior to the recent tide of rural-to-urban migration, a Household Registration (hukou) System imposes a strict restriction on individuals changing their permanent place of residence in China. In recent years, although the number of rural migrant workers in urban areas has increased dramatically, migrant workers still have great difficulty in obtaining urban registration. Households that live in urban areas but have no urban registrations were not sampled in the UHS before 2002. The sample coverage has been expanded since 2002 , but only slightly more than $1 \%$ of the individuals can be identified as migrant workers even in the expanded sample. Therefore, our sample is essentially restricted to urban households with urban registration. For this group of households, measurement error introduced by migration is very limited.

Our empirical focus is the identification of the effects of the three demographic variables,

including the numbers of adult children, dependent children, and siblings on household saving rates. The number of siblings is presumably exogenous to household saving decision, as one's 
current period saving decision is unrelated to the fertility decision of their parents. We thus concentrate on finding instruments for the number of adult children and the number of dependent children to address the bias caused by the endogenous fertility decision. China's population control policies substantially changed fertility for the cohorts exposed to the policies at their childbearing age. Important modifications have been made to the population control policies over time, and the means of implementation and vigor of enforcement of the policies differ greatly across provinces. The birth cohort and the province of residence jointly determine an individual's exposure to the population control policies. For example, a woman born in 1940 was 39 in 1979, when the one-child policy was first introduced. She had most likely passed her childbearing age, and the one-child policy should have a limited impact on her fertility decision. A woman born in 1960 was 19 in 1979, and was fully exposed to the policy. In addition, the intensity of the policy implementation measured by fines levied on unauthorized births varies greatly across provinces and over time (Scharping 2003, Ebenstein 2010). We exploit the exogenous variability in cohort-specific fertility generated by the different timing of population control policies that affected different birth cohorts and by the interaction of birth cohorts with fines across provinces on unauthorized births under the one-child policy. Specifically, we use the interactions of provincial-level fines for unauthorized births with cohort dummies as instruments to identify the effects of the numbers of adult and dependent children on household saving. The population control policies provide the possibility of implementing such a technique as they have induced changes in fertility that are systematically different across the cohorts and provinces that we consider. Our econometric approach and identification strategy are similar to those used by Attanasio and Brugiavini (2003), and Li and Zhang (2009). ${ }^{16}$

\footnotetext{
${ }^{16}$ Attanasio and Brugiavini (2003) exploit the differential effects of the 1992 Italian pension reform across cohorts and occupational groups to study household saving response. Li and Zhang (2009) also use the interaction of age with fertility fines as an instrumental variable to test the external effect of household demand for children.
} 


\subsection{Estimation Results}

We estimate our specification (7) on the cohort-based sample and report estimation results in Table 2. We instrument the number of adult children and the number of dependent children by the interactions of cohort dummies and provincial fertility fines measured as a ratio of annual household income. Individuals in our sample were born between 1930 and 1979. Cohort dummies are defined for each five-year cohort intervals. The instrumental variables include the interactions between province- and year-specific fine/income ratios and cohort dummies between 1945 and 1979, as women born before 1945 had likely passed the child-bearing ages by 1990 and were unaffected by fertility fines in either 1990 or 2005 . In the Appendix, we present the first-stage estimation results with the number of adult children and the number of dependent children as the dependent variables. In the first equation, all the seven instruments are negative and significant, suggesting that the fines have a negative effect on fertility for cohorts born after 1945. The fertility fine also has a negative and mostly significant effect on the number of dependent children for cohorts born between 1950 and 1979. In both regressions, the $F$-statistics for the joint test of the IVs are very large $[F(7,406)=97.32$ and $F(7,406)=24.61]$, which suggests that these IVs have a high explanatory power for the endogenous variables.

In Table 2, we regress saving rates on demographics and other control variables. The numbers of adult children and dependent children are first predicted using the full set of instrumental variables, including the interactions of seven cohort dummies with province-year fertility fines for excess birth. The table has six columns corresponding to six specifications with and without additional control variables. Standard errors are presented in the parentheses, and they are adjusted to take into account the use of the predicted values of numbers of adult and dependent children in the second stage. We let the coefficients on demographic structure be dependent on age intervals as in Equation (7), to allow for the possibility that the effects of demographic structural changes on household saving vary by age.

In column 1 of Table 2, we report regression results with only three demographic vari- 
ables interacted with selected age-interval dummies. The number of adult children has a significantly negative effect on saving for older households. One less child is associated with a rise in saving rate by 3.4 percentage points for those between age 51 and 55, and by 2.4 percentage points for those between age 56 and 60. In other words, as workers approach or reach retirement age, their saving decision begins to respond to the number of offspring they have as they start worrying about their own old-age security. Older households save more for the purpose of old-age security when they have fewer children. These results are consistent with Hypothesis 1. For households with dependent children, having less mouths to feed is generally associated with higher saving, but the effect is only significant for those between 41 and 50 years old. China adopts a nine-year compulsory school system. Public schools are relatively cheap, but the cost of college is substantial. This reality may explain our results, indicating that dependent children in their late teens and early 20 s cost the parents the most. ${ }^{17}$ This pattern is consistent with Hypothesis 2. The number of siblings has a negative and significant effect on saving rates for households between 26 and 40 years old. For workers who worry about old-age support of their parents, the burden for old-age care becomes eminent when their parents are reaching retirement age or have retired. If they have fewer siblings to share the responsibility of parental care, these workers need to save more. Our estimates indicate that one less sibling is associated with a 3.7 to 4.1 percentage points increase in saving rates for workers between 26 and 40 years old. These results confirm Hypothesis 3.

The three variables reflecting demographic structural changes have age-specific effects on household saving; thus, one might worry that age could affect saving rates directly, and the interaction terms are simply reflecting life-cycle patterns. In column 2 of Table 2, we add age and age squared as additional controls. The coefficients on both age and age squared are not statistically different from zero. The coefficients on the number of adult children, the

\footnotetext{
${ }^{17}$ Household expenditure data from UHS also reveal similar patterns. Among households that pay for schooling expenses, those headed by individuals between 41 and 50 years old pay the highest proportion (about 13\%) of their household income on education-related expenditure.
} 
number of dependent children, and the number of siblings are robust after we control for the life-cycle saving effects. The point estimates have the same sign and are close in magnitude compared to those in column 1.

Although the estimates in columns 1 and 2 have identified the effects of the demographic structural changes on household saving rates in China, we need to ensure that our estimates are not mainly picking up the effects of other omitted socioeconomic changes or policy shocks. Given that the exogenous variations in fertility come from the time- and province-specific fertility fines interacted with cohort dummies, concern might arise if the variables on adult and dependent children are simply proxies for other unobservable time and province effects. In column 3, we include the year and province effects as additional control variables. The number of adult children is observed to still have a significantly negative effect on household saving for those between 51 and 60 years old, although the point estimates are somewhat smaller compared to those in column 1 . The number of dependent children and the number of siblings have similar effects on saving rates as before when additional year and province effects are included.

In column 4, we include expected future earnings as an additional regressor to account for a life-cycle earning effect. We estimate the discounted present value of future earnings for each birth-year cohort in every province based on prevailing cross-sectional age-earnings profiles from the UHS and include them as an additional control variable. ${ }^{18}$ Column 4 of Table 2 shows that the estimated effects of demographic structure on household saving from this augmented model do not change significantly, except for the adult children effects on those households between 56 and 60 years old. Moreover, individuals who expect high future earnings tend to save less, although the estimated effects are not statistically significant.

Other factors have been widely used to explain saving patterns. In column 5 of Table 2, we include the proportion of individuals with high school or above education and the

\footnotetext{
${ }^{18}$ For simplicity, we assume that the prediction for future earnings is based on myopic expectation. Let $y_{a, j, t}$ be the average earnings of individuals of age $a$ in province $j$ at time $t$. For this age cohort in province $j$, their expected future earnings are determined by $\sum_{i=1}^{60-a} \frac{1}{(1+r)^{i}} y_{a+i, j, t}$ where $r$ is the discount rate set at 0.97 .
} 
proportion of minorities as proxies for saving preferences and welfare conditions, and local sex ratios to capture potential competitive saving motive (Wei and Zhang 2011). We find that households with at least high school education save more than those with lower education, which is consistent with patterns found in other countries. Saving rates of minorities are not statistically different from those of Hans. The local sex ratio has a significantly positive effect on saving rate, which is consistent with the findings in Wei and Zhang (2011).

The existing literature has hypothesized that job uncertainty motivates the Chinese to save more. In column 6 , we use the proportion of individuals who work for state-owned firms or government agencies as a proxy for the degree of job security. The argument that declining social security can contribute to rising saving in China has also been put forward (Chamon and Prasad, 2010; Song and Yang, 2010). We thus include per capita government spending on social security in a province as a proxy for the extent of the local social safety net. Under the precautionary saving hypothesis, saving rates should decline with better job security and better social security coverage. Both estimated coefficients are negative and statistically significant. These results support the precautionary saving motive, but the coefficients on demographic variables interacted with selected age-interval dummies remain negative and statistically significant. This outcome suggests that the effects of demographic changes on saving are robust to the precautionary saving motive.

To summarize, we find strong evidence on the age-specific effects of demographic structural changes on household saving rates in China. In particular, households between 51 and 60 years old will increase their saving rates for the purpose of old-age security if they have fewer adult children. The saving rates of middle-aged households between 41 and 50 years old will increase if they have fewer dependent children to raise. Younger households between 26 and 40 years old will save more when they have fewer siblings because of the increased burden of parental care. These patterns confirm the three hypotheses posited in the model. They are also robust to additional controls on life-cycle saving pattern, expected future earnings, time and province effects, and other factors posited in the literature, such 
as competitive saving motive and precautionary saving motive.

\subsection{Robustness Checks}

Results in Table 2 indicate that older households save more for their old-age security when they have fewer adult children. Sons are believed to provide more support to parents than daughters, which is one reason why traditional son preference is widespread in China; households with more sons would save less if old-age security is the main saving motive. In column 1 of Table 3, we examine whether the gender composition of children affects household saving by including the proportion of sons interacted with age-interval dummies between age 46 and 60 as additional control variables. The estimated coefficients on age-specific demographic variables have the same sign and similar magnitude as before. Specifically, households aged above 50 are found to save more when they have fewer children, even conditional on the gender composition of the children. We find some evidence that households between 46 and 50 years old will save less if they have more sons, conditional on the number of children. These results reinforce the old-age security motive.

Some support for the precautionary saving motive among Chinese households has been found. Job security (state employment) and social safety net (public spending on social security) are associated with lower (precautionary) saving. Saving for old-age security motive is essentially one type of precautionary saving. When having a child is a substitute for saving, having fewer children is associated with a rise in saving to secure old-age support. Therefore, with job security and social safety net, households may rely less on children for old-age security. In columns 2 and 3 of Table 3 , we test for this implication using the interactions between state employment share and the number of adult children, and the interactions between public spending on social security and the number of adult children for households between 46 and 60 years old as additional regressors. The estimated effects of demographic structural changes on saving are robust to these additional controls. In addition, the marginal effect of adult children on saving is lower (in absolute term) for 
state sector employees (between age 46 and 50) and for those enjoying higher social security (between age 56 and 60). These findings are consistent with the old-age security motive.

Our empirical results rely on the identification assumption that no omitted time-varying and province-specific effects are correlated with the interaction of birth cohorts with the fines for excess birth. The fertility fines may depend on local (unobserved) demographic, social, and economic conditions. Therefore, the identification assumption will be violated if saving decisions are correlated with these initial conditions, and it might be satisfied only after controlling for these factors. Generally, completely solving this problem is very difficult because many of the variables may not be observable or known to researchers. However, in

columns 3 to 6 of Table 2, the flexible province and year dummies should capture most of these effects. The spatial and time variations in the fertility fines may also be affected by past birth rates. Thus, we present in columns 1 to 6 of Table 4 the specifications that control for provincial birth rates in the previous year. After controlling for past birth rates, the estimates on age-specific effects of demographic structure on saving remain close to those presented in Table 2. Moreover, the coefficient on birth rates in the previous year is not significantly different from zero, except in one of the six specifications.

\subsection{Implications on Changes in Saving Profile}

Combining the estimated effects of demographic changes on saving in Table 2 and trends in the numbers of children ever born, dependent children, and siblings as presented in Figures 5 to 7 , we can conduct a "back-of-the-envelope" calculation on how much the demographic structure changes can account for the upward shift in age-saving profile between 1990 and 2005. For each five-year age group, the point estimates in Table 2 present the marginal effects of the demographic structural changes on household saving. That is, the changes in saving rates in percentage points associated with each additional adult child, dependent child, or sibling. Using information from Figures 5 to 7, we can derive the average changes in the numbers of children, dependent children, and siblings induced by population policies 
and other socioeconomic changes between 1990 and 2005 for each age group. The product of the marginal effects and the average demographic changes are the effects of demographic structural changes on age-saving profile shifts between 1990 and 2005 implied by our estimates.

For households with the age of their heads between 26 and 30 years old, having one more sibling is associated with a 3.25 (specification 3) to 4.26 (specification 2) percentage points decrease in saving rates depending on different empirical specifications. A decrease in the number of siblings for households between 26 and 30 years old from 3.64 in 1990 to 1.60 in 2005, as illustrated in Figure 7, would lead to a rise in saving rate by 6.63 $[=3.25 \times(3.64-1.60)]$ to $8.69[=4.26 \times(3.64-1.60)]$ percentage points, accounting for large portions of the actual increase in the average saving rates from $13.25 \%$ in 1990 to $24.89 \%$ in 2005. Similarly, for household heads between 31 and 35 years old, having one more sibling is associated with a 2.70 to 3.72 percentage points decrease in the saving rate. Therefore, the observed decrease of 1.75 siblings for this age cohort from 1990 to 2005 would lead to a rise in saving rate by 4.73 to 6.51 percentage points, accounting for a significant portion of the actual 10.77 percentage points increase in saving rates. The decline in sibling size is also statistically important for explaining the rise in saving rate for households with the age of their heads between 36 and 40 years old.

For households with the age of their heads between 41 and 45 years old, having one more dependent child is associated with a 12.11 to 17.57 percentage points decrease in saving rates. Given that the number of dependent children for these households decreased from 1.01 in 1990 to 0.63 in 2005, as illustrated in Figure 6, this factor would lead to higher saving rates by 4.60 to 6.68 percentage points across different specifications. In comparison, the observed average saving rates increased by 5.14 percentage points from $16.03 \%$ in 1990 to $21.17 \%$ in 2005. Similarly, the decrease in the number of dependent children is also a significant contributor to the rise in saving rate for households between 46 and 50 years old.

For households between 51 and 55 years old, having one more adult child is associated 
with a 2.35 to 4.61 percentage points decrease in saving rates. The decrease in the number of adult children from 3.30 in 1990 to 1.54 in 2005, as illustrated in Figure 5, would lead to a rise in saving rate by 4.14 to 8.11 percentage points because of reduced old-age support. The lower-bound estimates would account for $63 \%$ of the actual increase (4.14 out of 6.55 ) in saving rates from 1990 to 2005, whereas the upper-bound estimates would over-predict the saving increase. Furthermore, for households between 56 and 60 years old, having one more adult child is associated with a 1.95 (insignificant) to 4.42 percentage points decrease in saving rates. A decrease in their fertility from 3.84 to 2.03 would imply an increase in the saving rate ranging from 3.53 to 8.00 percentage points, accounting for $40 \%$ to $92 \%$ of the actual increase.

These calculations indicate that all three dimensions of the demographic structural changes have quantitatively important and age-specific effects on the U-shaped rise in agesaving profile between 1990 and 2005. It is not surprising that the three demographic variables alone cannot fully explain the changes in saving profile because many other socioeconomic factors have influenced household saving behavior over time as we have also found in Table 2.

The "back of the envelope" calculations need to be interpreted cautiously as they are based on point estimates, and the instrumental variable estimator is known to identify only the local average treatment effect (Imbens and Angrist 1994). Therefore, the quantitative extrapolations are only suggestive. Nevertheless, we qualitatively show that the demographic structural changes can partially capture the overall rise in saving rates and the U-shaped increases of the age-saving profile between 1990 and 2005. In particular, the saving rates of younger households increase because of the rising burden of parental care with fewer siblings; middle-aged households save more as they have fewer dependent children to support; and older households with a reduced number of adult children increase their saving rates because of old-age security concerns. 


\section{Conclusion}

In this paper, to resolve the Chinese household saving puzzle, we have postulated and estimated the effects of demographic changes on household saving in China. To this end, we have studied China's population policies. The population control policies substantially changed the number of children Chinese households have. We exploit the variation in the changes in fertility for households from several birth cohorts and across provinces to identify the effects

of demographic structural change on saving rates. The results indicate that demographic structural changes have age-specific effects on household saving decisions. When we use the estimated model to investigate the changes in household saving profile between 1990 and 2005, we find that younger households save more because of the rising burden of parental care with fewer siblings. Middle-aged households save more as they have fewer dependent children to support. Older households with a reduced number of adult children save more because of old-age security concerns.

As the one-child policy approaches the third generation, the "4-2-1" type of family structure becomes more pervasive, that is, a family with one child, two parents, and four grandparents. One unanticipated consequence of the population control policies is perhaps the increasing household saving. Our paper provides a new rationale for the relaxation of the one-child policy: removing the birth quota could potentially stimulate household consumption and substantially fuel current domestic demand. 


\section{References}

Attanasio, Orazio P. (1998). "Cohort Analysis of Saving Behavior by U.S. Households." Journal of Human Resources, 33(3): 575-609.

Attanasio, Orazio P., and Agar Brugiavini (2003). "Social Security and Households' Saving." Quarterly Journal of Economics, 118(3): 1075-1119.

Banerjee, Abhijit, Xin Meng, and Nancy Qian (2010). "The Life Cycle Model and Household Savings: Micro Evidence from Urban China." Working paper, Yale University.

Chamon, Marcos, and Eswar Prasad (2010). "Why Are Saving Rates of Urban Households in China Rising?" American Economic Journal: Macroeconomics, 2(1): 93-130.

Chen, Binkai, Ming Lu, and Ninghua Zhong (2012). "Hukou and Consumption Heterogeneity: Migrants' Expenditure is Depressed by Institutional Constraints in Urban China." Working paper. Available at SSRN: http://ssrn.com/abstract=1989257 or http://dx.doi.org/10.2139/ssrn.19892

Coale, Ansley J. (1984). "Rapid Population Change in China, 1952-1982." National Academy Press, Washington, D.C.

Curtis, Chadwick C., Steven Lugauer, and Nelson C. Mark (2011). "Demographic Patterns and Household Saving in China." Working paper, University of Notre Dame.

Ebenstein, Avraham (2010). "The 'Missing Girls' of China and the Unintended Consequences of the One Child Policy." Journal of Human Resources, 45(1): 87-115.

Gu, Baochang, Feng Wang, Zhigang Guo, and Erli Zhang (2007). "China's Local and National Fertility Policies at the End of the Twentieth Century." Population and Development Review, 33(1): 129-147.

Hesketh, Therese, Lu Li, and Wei Xing Zhu (2005). "The Effect of China's One-Child Family Policy after 25 Years." New England Journal of Medicine, 353(11): 1171-1176. 
Horioka, Charles Yuji, and Junmin Wan (2007). "The Determinants of Household Saving in China: A Dynamic Panel Analysis of Provincial Data." Journal of Money, Credit and Banking, 39(8): 2077-2096.

Imbens, Guido W., and Joshua D. Angrist (1994). "Identification and Estimation of Local Average Treatment Effects." Econometrica, 62(2): 467-475.

Jappelli, Tullio, and Franco Modigliani (2005). "The Age-Saving Profile and the Life-Cycle Hypothesis." In The Collected Papers of Franco Modigliani, Volume 6. Cambridge, Massachusetts: The MIT Press: 141-172.

Li, Hongbin, Junjian Yi, and Junsen Zhang (2011). "Estimating the Effect of the OneChild Policy on Sex Ratio Imbalance in China: Identification Based on the Difference-inDifferences." Demography, 48(4): 1535-1557.

Li, Hongbin, and Junsen Zhang (2009). "Testing the External Effect of Household Behavior: The Case of the Demand for Children." Journal of Human Resources 44(4): 890-915.

Modigliani, Franco, and Shi Larry Cao (2004). "The Chinese Saving Puzzle and the LifeCycle Hypothesis." Journal of Economic Literature, 42(1): 145-170.

Scharping, Thomas (2003). "Birth Control in China 1949-2000: Population Policy and Demographic Development." New York, NY: Routledge Curzon.

Short, Susan E., and Fengying Zhai (1998). "Looking Locally at China's One-Child Policy." Studies in Family Planning 29(4): 373-387.

Song, Zheng, Kjetil Storesletten, Yikai Wang, and Fabrizio Zilibotti (2012). "Sharing High Growth Across Generations: Pensions and Demographic Transition in China." Working paper, University of Zurich.

Song, Zheng, and Dennis Tao Yang (2010). "Life Cycle Earnings and Saving in a FastGrowing Economy." Working paper, Chinese University of Hong Kong. 
United Nations (2008). World Population Prospects, the 2008 Revision. Population Division, Department of Economic and Social Affairs, United Nations. http://esa.un.org/unpp.

Wei, Shang-Jin, and Xiaobo Zhang (2011). "The Competitive Saving Motive: Evidence from Rising Sex Ratios and Savings Rates in China." Journal of Political Economy, 119(3): $511-564$.

Yang, Dennis Tao, and Dandan Chen (2004). "Transformations in China's Population Policies and Demographic Structure." Pacific Economic Review, 9(3): 269-290.

Yang, Dennis Tao, Junsen Zhang, and Shaojie Zhou (2012). "Why Are Saving Rates So High in China?" In Chapter 5 of Capitalizing China, edited by Joseph P. H. Fan and Randall Morck. Chicago: University Of Chicago Press: 249-278. 
A. Average Household Saving Rates in 1989-1991 and 2004-2006

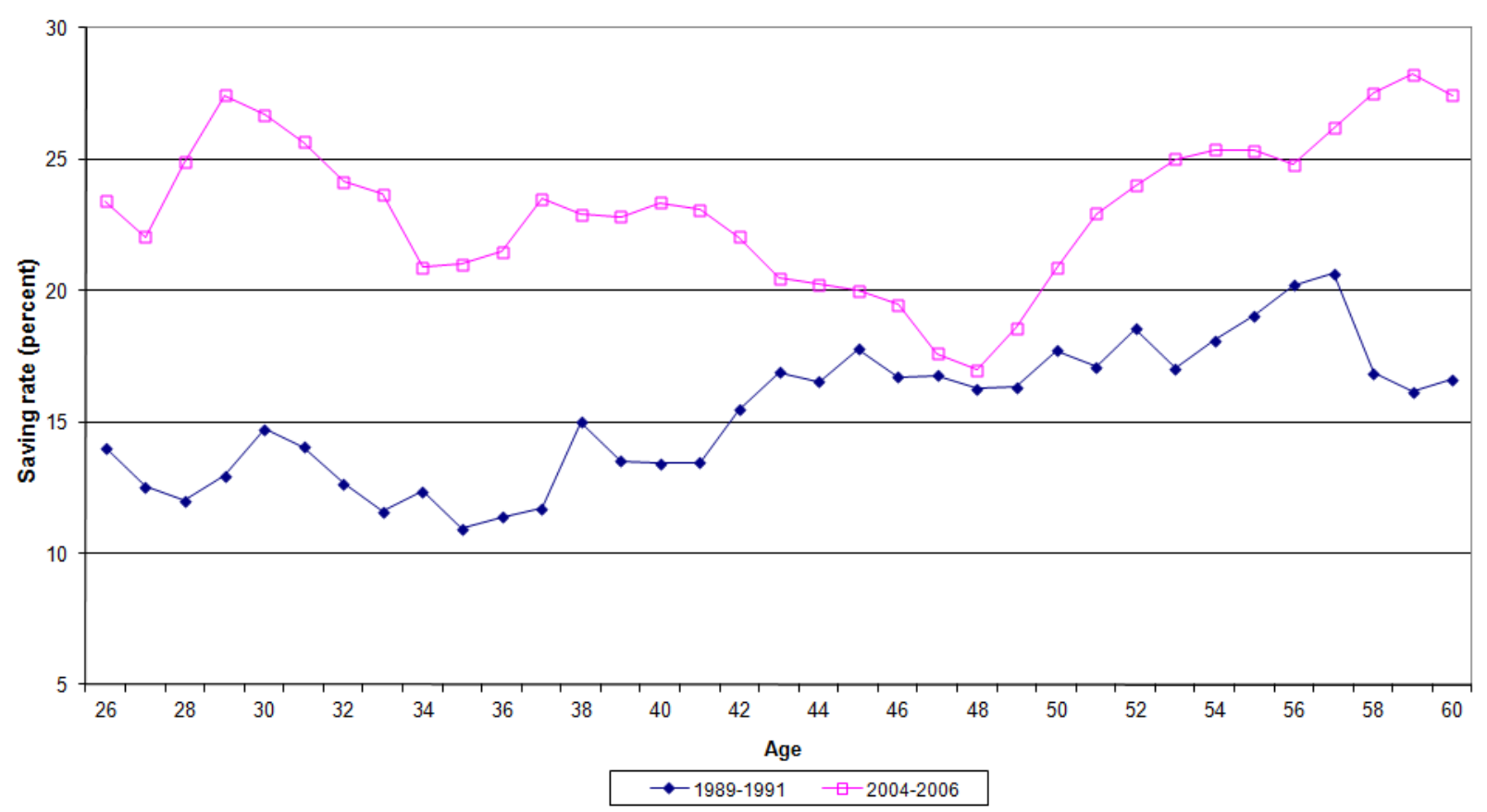

B. Increase in Household Saving Rates from 1989-1991 to 2004-2006

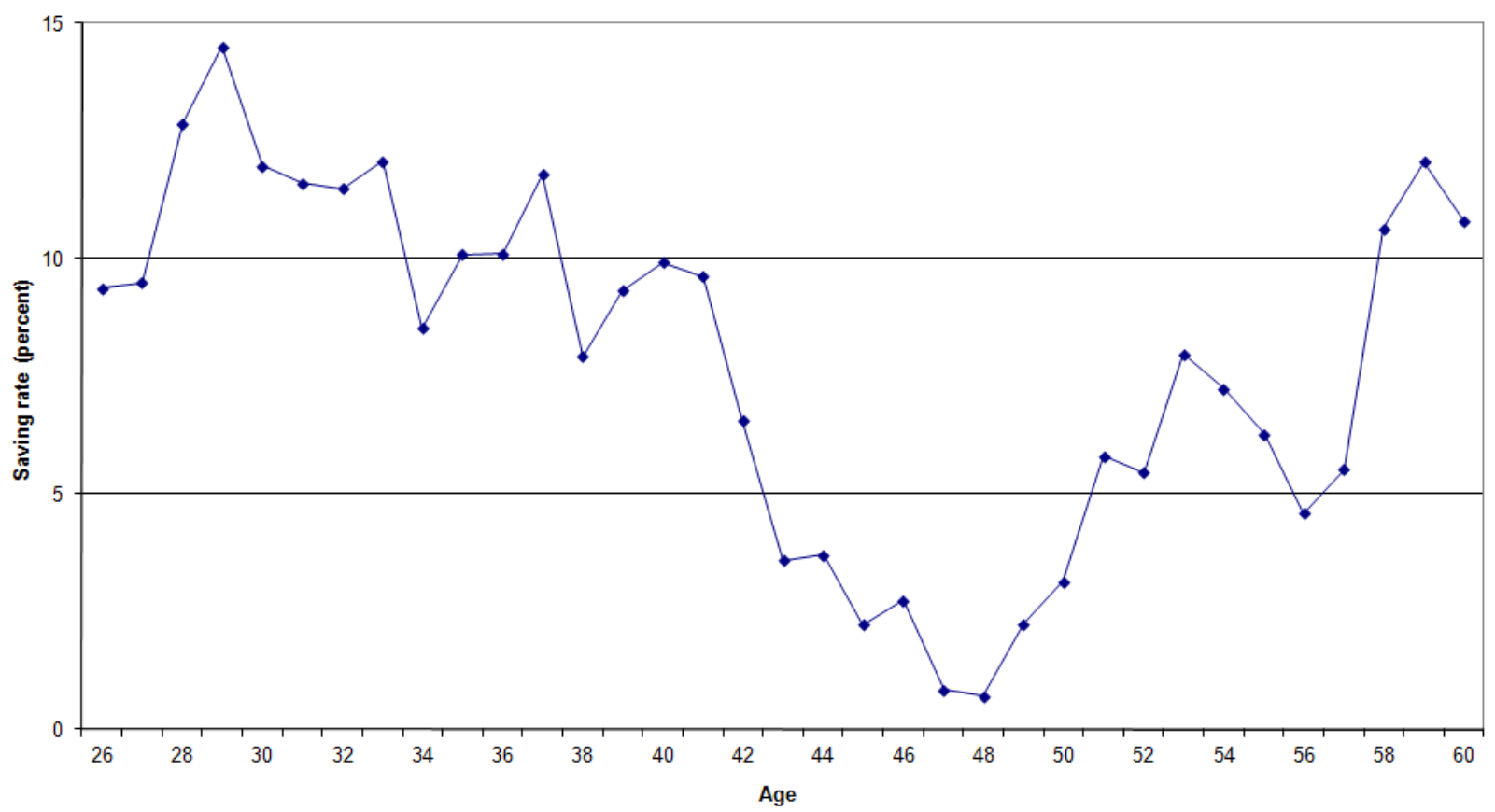

Figure 1. Age-Saving Profiles and Their Changes Over Time 


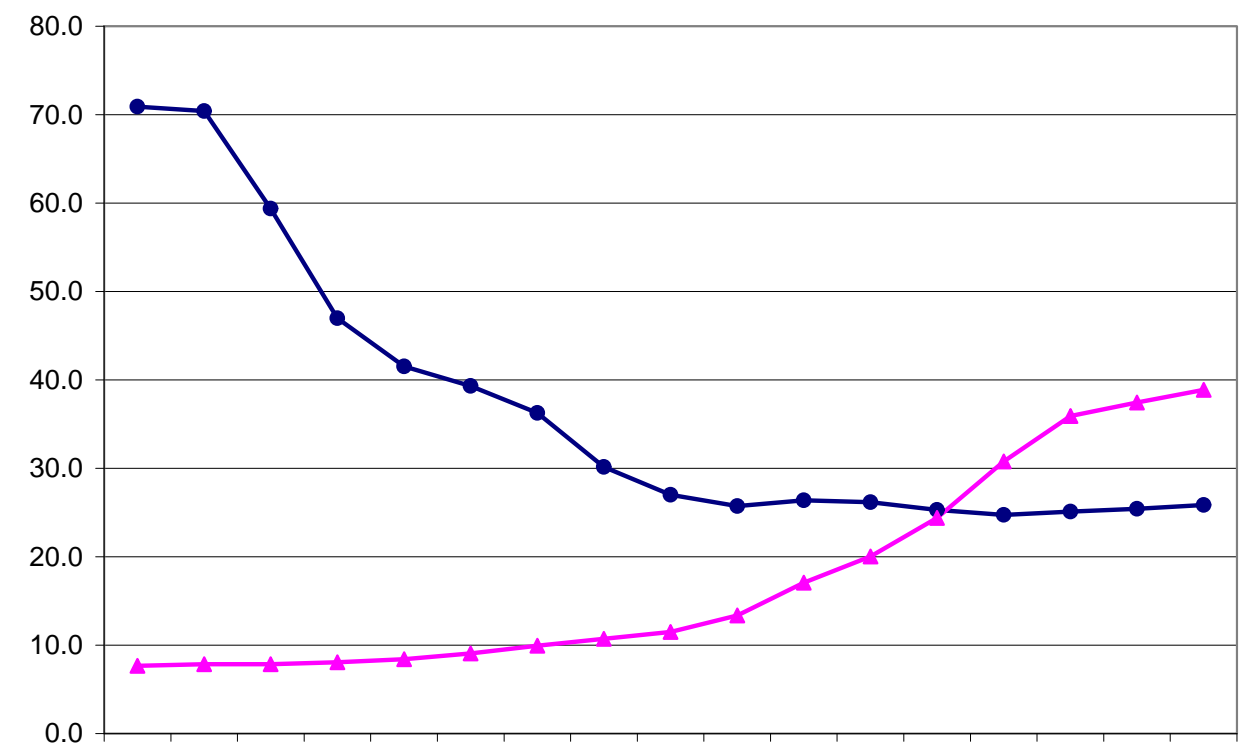

19701975198019851990199520002005201020152020202520302035204020452050

$\rightarrow$ Young dependency ratio $\rightarrow$ Old dependency ratio

Source: Population Division of the Department of Economic and Social Affairs of the United Nations Secretariat, World Population Prospects: The 2008 Revision, http://esa.un.org/unpp.

Figure 2. China's Long-Term Population Trends: 1970 to 2050 

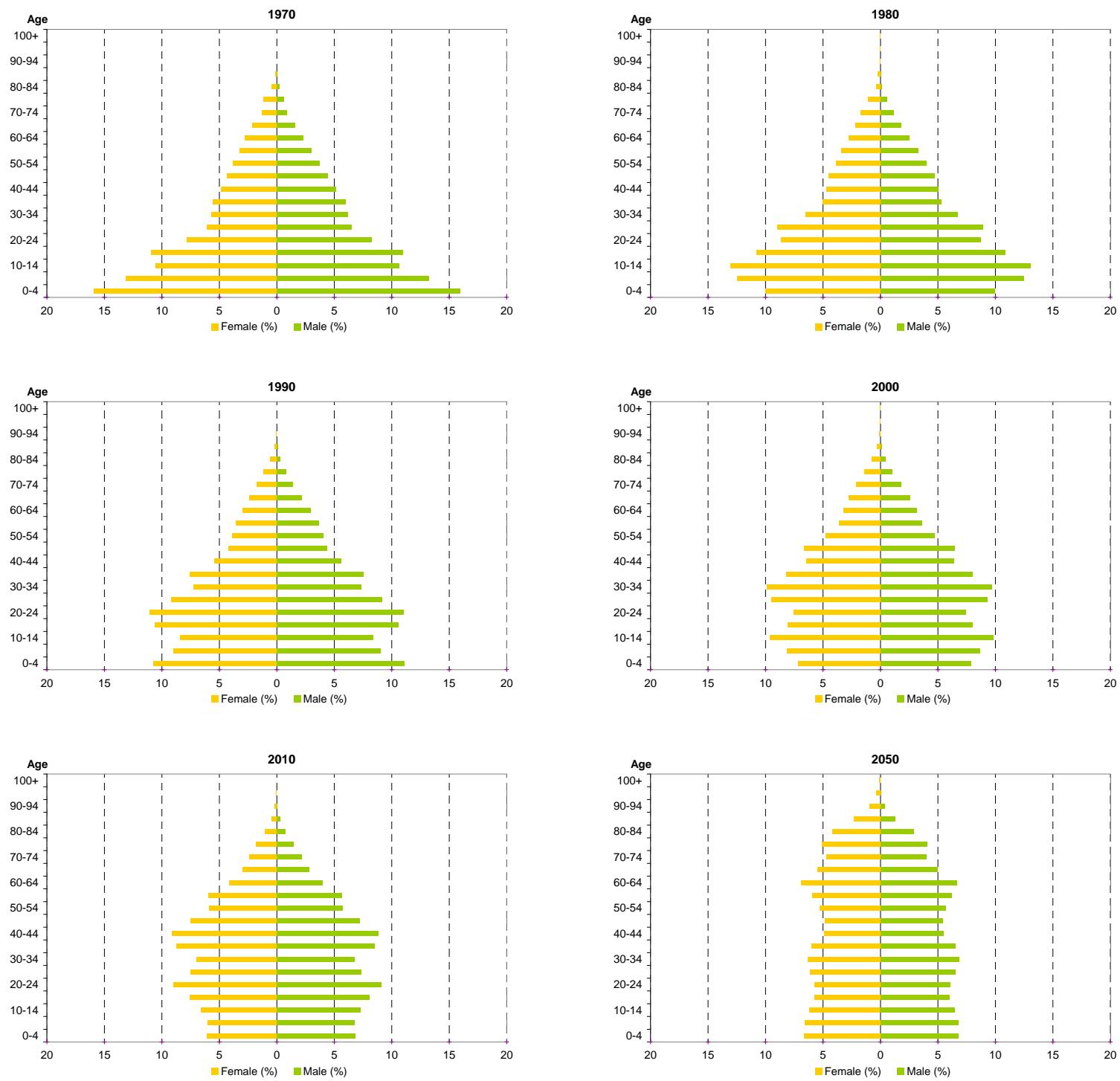

Figure 3. Age Distribution of the Chinese Population: 1970 to 2050 


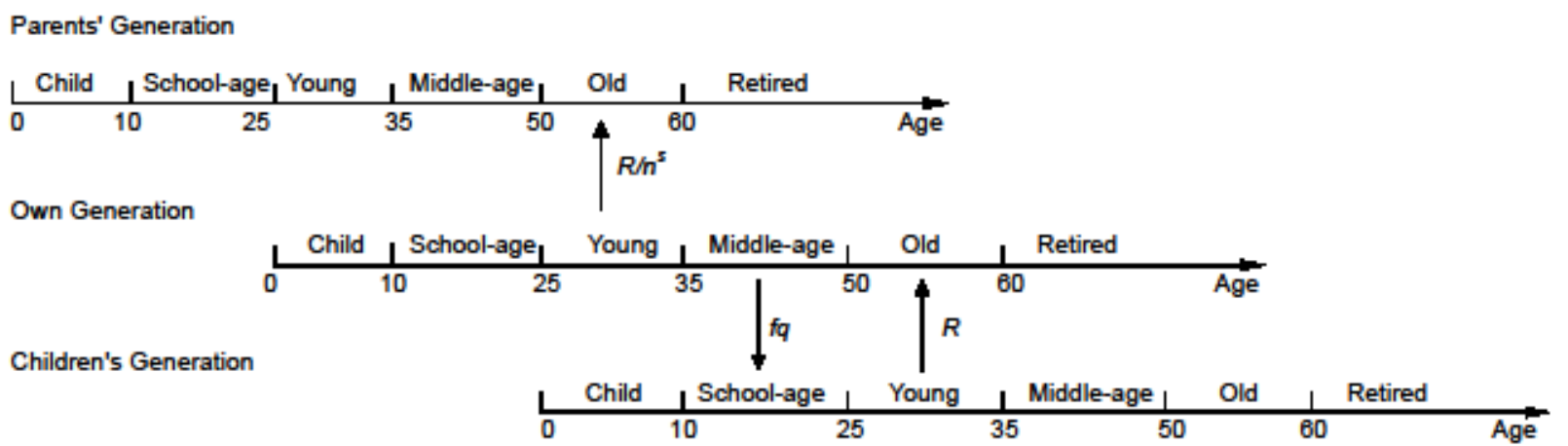

Figure 4. Inter-Generational Links 


\section{A. Average Number of Children Ever Born in 1990 and 2005}

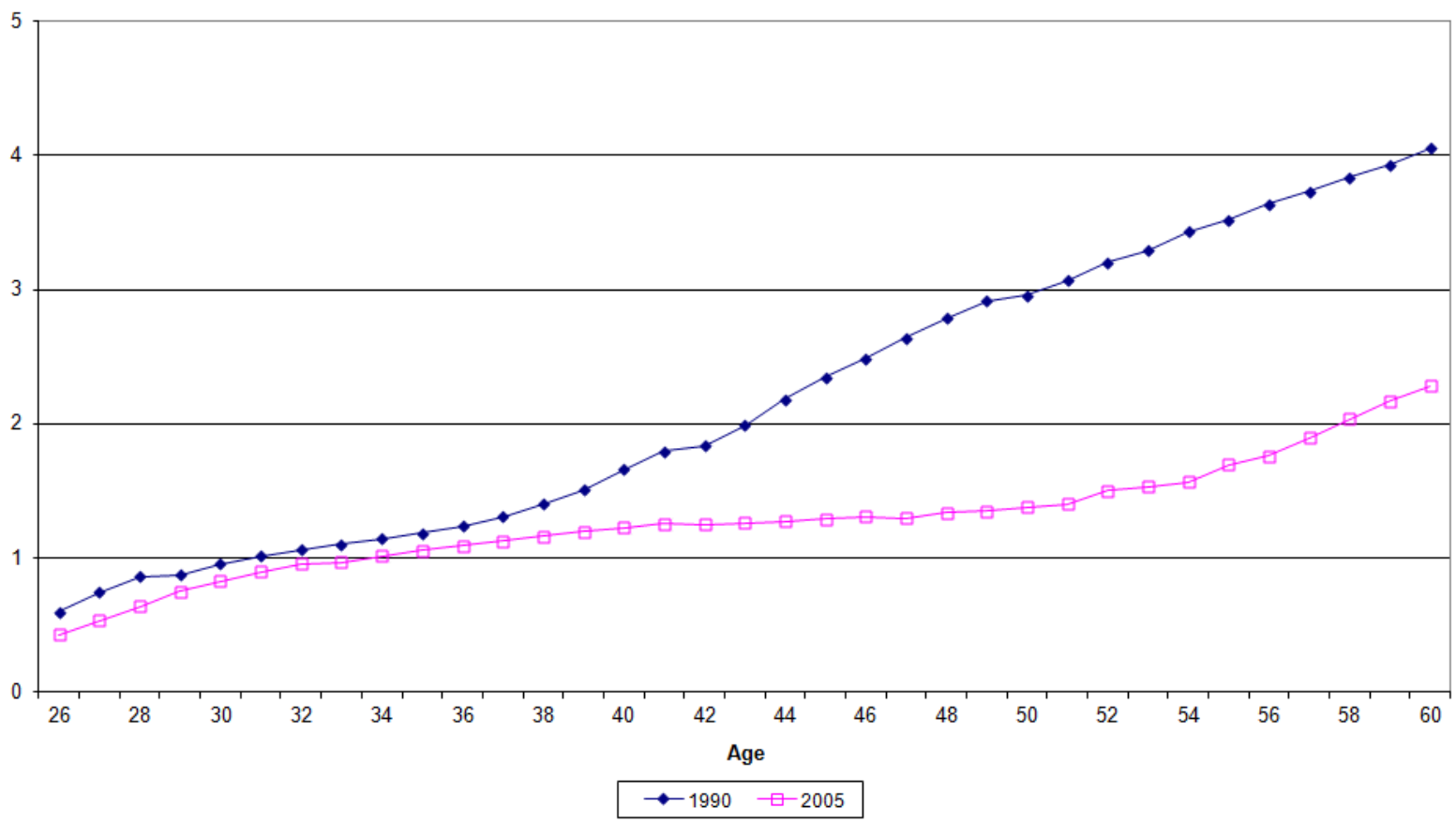

B. Changes in Average Number of Children Ever Born from 1990 to 2005

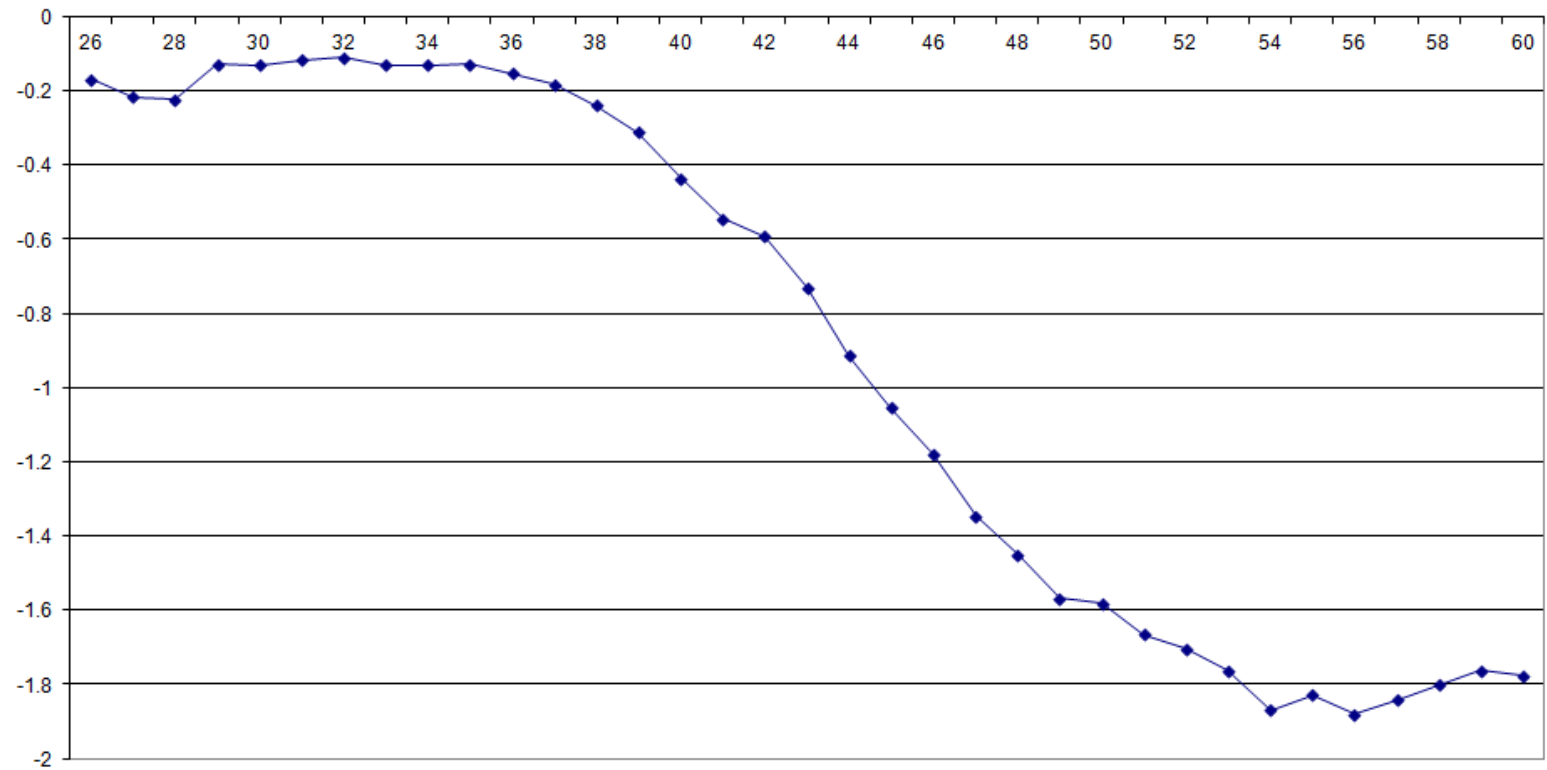

Age

Figure 5. Average Number of Children Profiles and Their Changes Over Time 


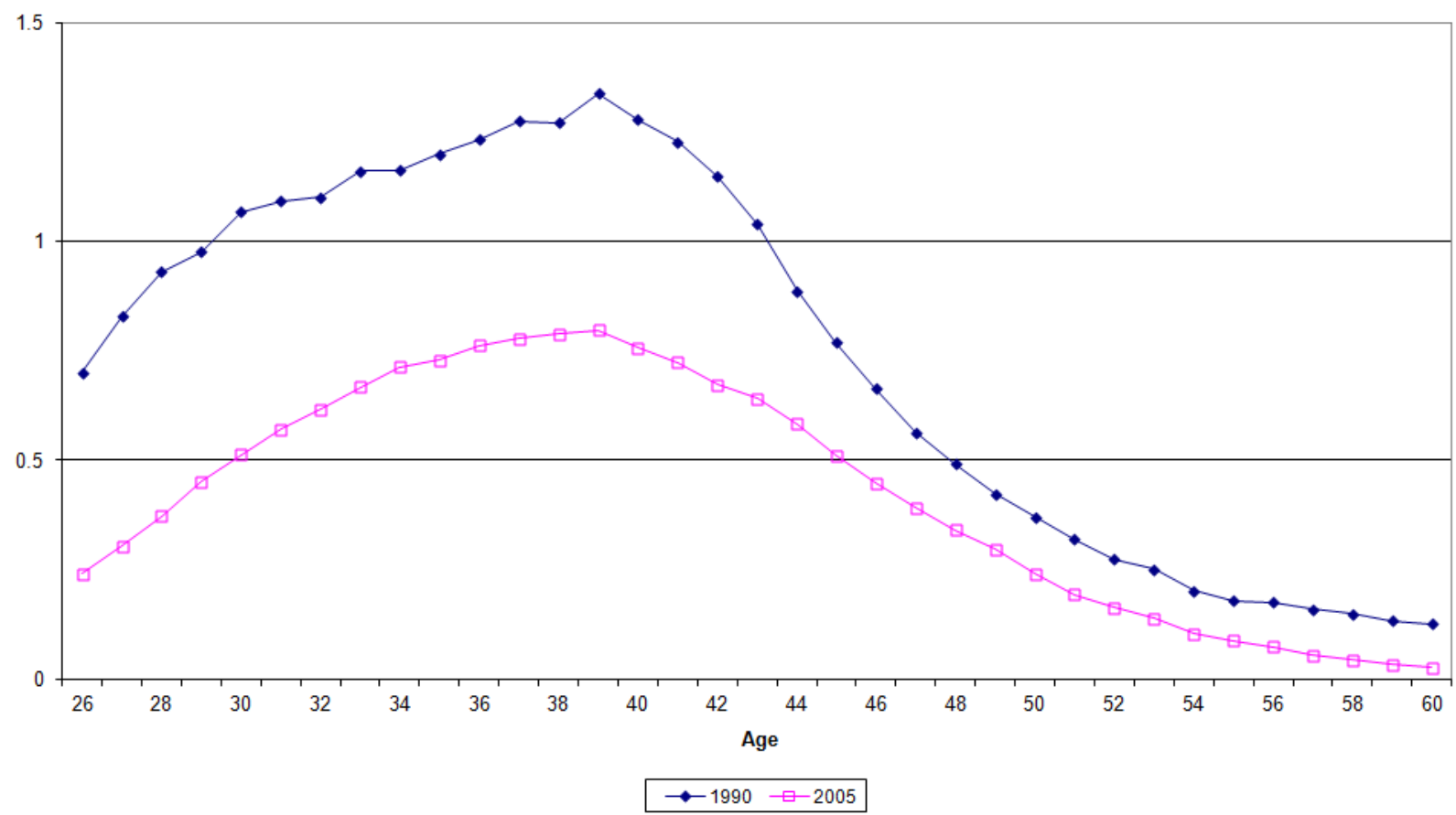

B. Changes in Number of Dependent Children from 1990 to 2005

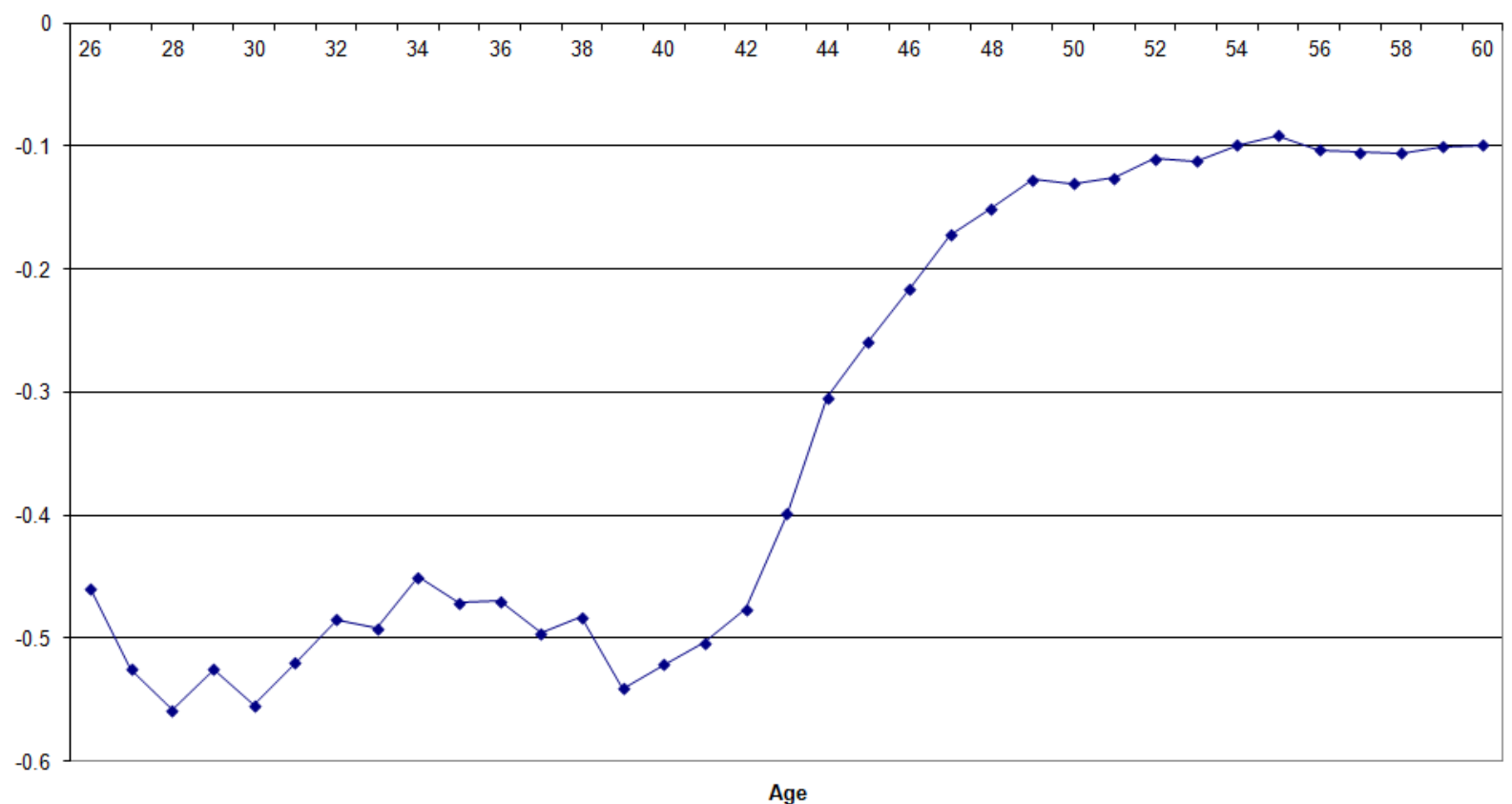

Figure 6. Number of Dependent Children Profiles and Their Changes Over Time 
A. Average Number of Siblings in 1990 and 2005

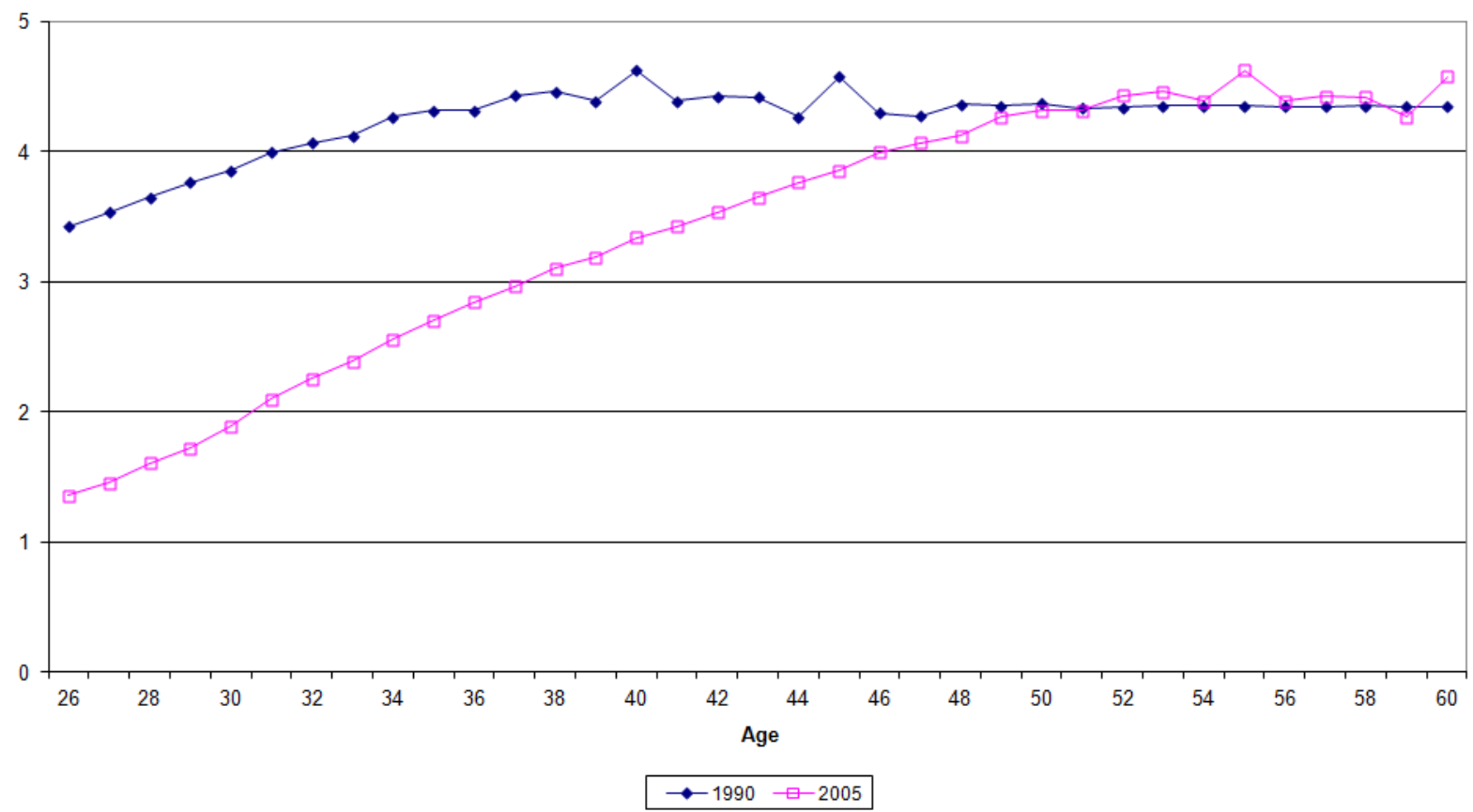

B. Changes in Number of Siblings from 1990 to 2005

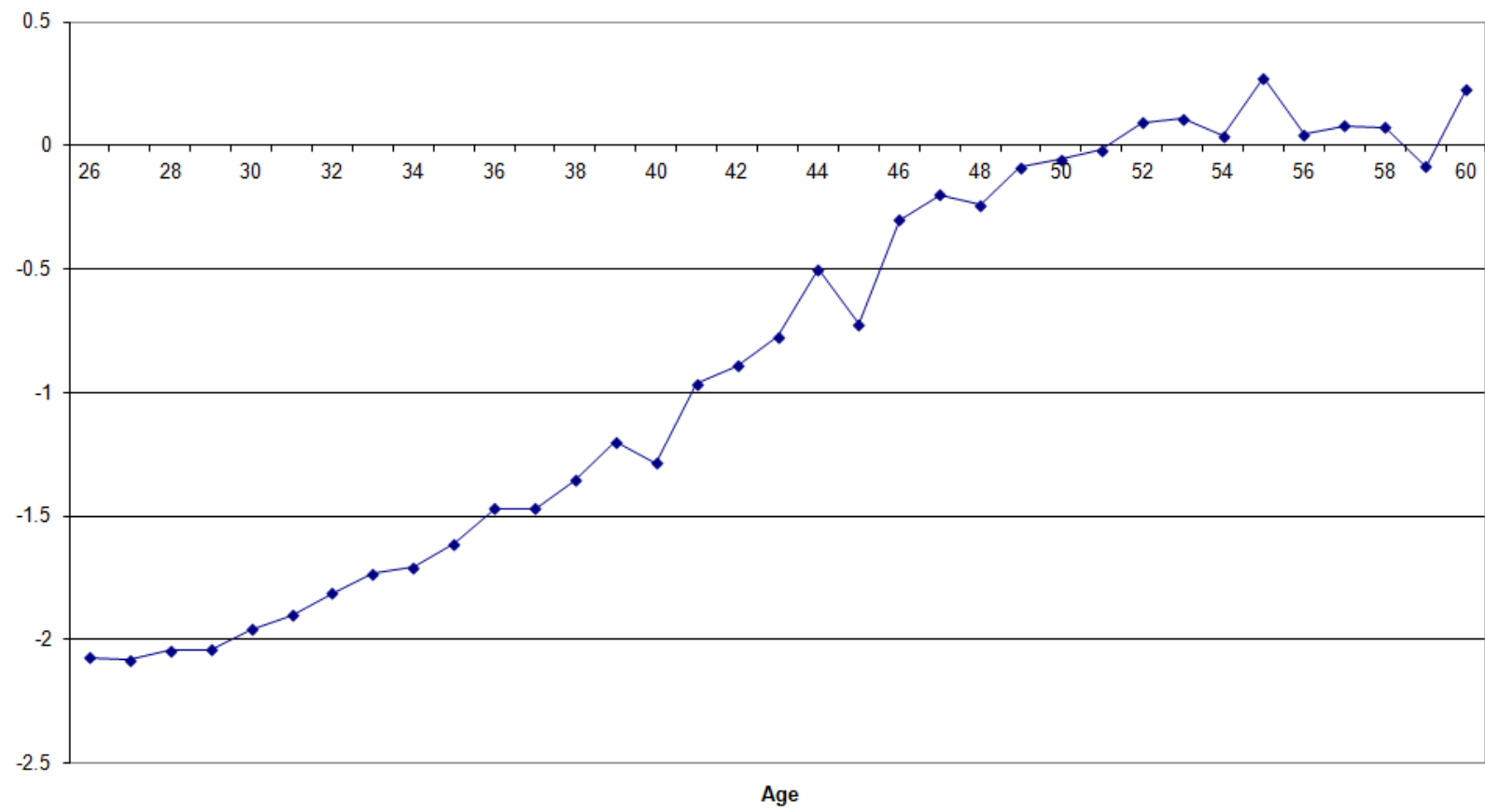

Figure 7. Number of Siblings Profiles and Their Changes Over Time 